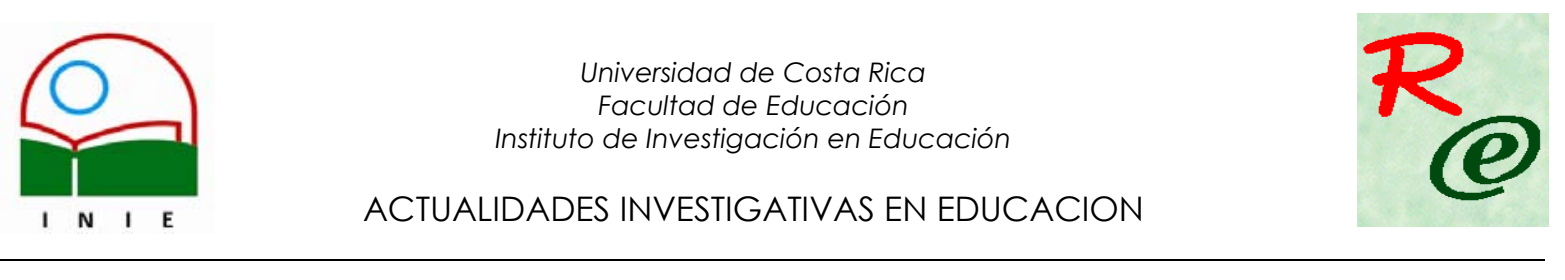

\title{
LOS TRASTORNOS DE LA ATENCIÓN CON O SIN HIPERACTIVIDAD: UNA MIRADA TEÓRICA DESDE LO PEDAGOGICO
}

\author{
THE ATTENTIONAL AND EDUCATIONAL DISORDERS WITH OR WITHOUT \\ HYPERACTIVITY: A THEORETICAL GLANCE FROM THE PEDAGOGICAL APPROACH
}

Carmen María Cubero Venegas ${ }^{1}$

\begin{abstract}
Resumen: En el trabajo con las personas profesionales en educación al abordar el tema del déficit de atención, surgen múltiples opiniones, muchas de ellas matizadas por los mitos y por las ideas falsas que han rodeado en los últimos 100 años al trastorno del déficit de atención con o sin hiperactividad. El objetivo propuesto, en este artículo, es intentar construir un referente pedagógico que sirva de base teórica al conocimiento, a la discusión y a la atención de la población escolar que tiene las características de este trastorno y que precisan día a día del compromiso solidario de sus maestras, sus maestros y su familia.

En el artículo se propone una aproximación a la visión que históricamente ha tenido el trastorno del déficit de atención, las causas y las consecuencias en lo emocional, social y académico. Se mira el trastorno a partir del papel explicativo que permite el análisis de cuatro de las funciones ejecutivas de mayor relevancia para la comprensión de las características del trastorno: la memoria de trabajo, el desarrollo del lenguaje interno, las habilidades de autorregulación de las emociones y la motivación y de la habilidad para la resolución de problemas.
\end{abstract}

Palabras clave: TRASTORNOS DE LA ATENCIÓN Y EDUCACION/ DEFICIT DE ATENCION/ DÉFICIT DE ATENCIÓN CON O SIN HIPERACTIVIDAD/ DÉFICIT DE ATENCIÓN Y ESCUELA/ FUNCIONES EJECUTIVAS/ MEMORIA DE TRABAJO/ LENGUAJE INTERNO, AUTORREGULACION/ RESOLUCION DE PROBLEMAS/

\begin{abstract}
A lot of different opinions rise when you talk about DA, while working with people dedicated professionally to the education; lots of those opinions are shade by the myths and false ideas that has surrounded $D A$ in the last 100 years, with or without hyperactivity. The proposed objective in this article, is trying to build a pedagogic referent that can be used as a teorical base to the knowledge, discussion and attention of the scholar population that has the characteristics of this disorder, and that long for the solidary compromise of their teachers and family.

In the article is proposed an approach to the historic vision of the DA disorder, as its causes and consequences in the social, academic and emotional sense. This disorder is look from the explaining sense that allows the analysis of four of the major executive functions to the comprehension of the characteristics of this disorder: the work memory, the inner language development, the skills to self-regulation of the emotions and motivations and the problem solving skills.
\end{abstract}

Key words: ATTENTIONAL AND EDUCATIONAL DISORDERS/ ATTENTION DEFICITI ATTENTIONAL DEFICIT WITH OR WITHOUT HYPERACTIVITYI ATTENTIONAL DEFICIT AND SCHOOL/ EXECUTIVE FUNCTIONS/INNER LANGUAGE/ SELF REGULATION/ PROBLEM SOLVING/

\footnotetext{
${ }^{1}$ Licenciada en Psicología de la Universidad de Costa Rica. Profesora de Enseñanza Media de Universidad de Costa Rica. Estudios de Maestría en Administración Pública en el Instituto Centroamericano de Administración Pública. Profesora de la Escuela de Orientación y Educación Especial, Sección de Psicopedagogía de la Universidad de Costa Rica. Subdirectora del Instituto de Investigación en Educación (INIE), de la Universidad de Costa Rica.
}

Correo electrónico: ccubero@cariari.ucr.ac.cr

Artículo recibido: 18 de enero, 2006

Aprobado: 27 de abril, 2006 


\section{Introducción}

Al revisar la literatura, pensando en cual información se necesita para comprender y entender, desde el centro educativo, lo que se ha llamado trastornos de la atención, o bien déficit de atención con o sin hiperactividad, y lograr facilitar el proceso de enseñanza y de aprendizaje de las personas con esta condición, se encuentra una gran cantidad de literatura, tanto en documentos físicos como en la Internet. Alguna de esta información es muy valiosa y se encuentra cuidadosamente elaboradora. Otra, por el contrario, deja serias dudas en el lector. La razón inspiradora de este artículo es poder ofrecer al lector aportes diversos que enriquezcan y guíen el estudio y la reflexión de los profesionales en educación que deben, día a día, buscar alternativas que permitan que las personas puedan demostrar sus capacidades, sus habilidades y sus potencialidades de manera diferente de sus coetáneos, y sin que el entorno invisibilice sus posibilidades.

Al tratar de definir qué es lo que se entiende por déficit de atención, se encontraron múltiples propuestas. La autora ha realizado una selección de algunas de ellas que abordan diversos aspectos importantes para la comprensión del trastorno desde un entorno educativo. García Pérez y Magaz Lago, (2001) proponen que el déficit de atención es un conjunto de diversas manifestaciones conductuales. No lo consideran un síndrome conductual únicamente, sino un conjunto de problemas relacionados entre sí. El Instituto Nacional de Salud Mental de los Estados Unidos (2002) señala que es una incapacidad que afecta la habilidad de los niños de aprender y obrar recíprocamente con otros, y propone que puede ser una condición incapacitante. Por su parte, el Centro de Investigación en Medicamentos (CIMED) de la Universidad de Costa Rica (2002), ante una consulta realizada, propone que el déficit de atención es un patrón persistente y frecuente de falta de atención e impulsividad inapropiadas para el grado de desarrollo esperable de los individuos, puede presentarse con o sin hiperactividad. En el Centro indican también que puede estar acompañado de problemas específicos de aprendizaje, con inteligencia normal, con alteraciones de conducta, inmadurez, déficit perceptuales, motores y de coordinación, inestabilidad emocional, dificultades con los compañeros, baja autoestima, baja tolerancia a la frustración y, especialmente, está asociado al fracaso escolar.

García Pérez (2001) manifiesta que es una condición biológica que afecta, primordialmente, la capacidad del escolar para focalizar eficazmente y mantener la atención un tiempo razonable en una tarea que se le propone. Tanto el Déficit de Atención (DA) como el Déficit de Atención con hiperactividad (DAH), afectan gravemente la capacidad para aprender, constituyendo un factor aptitudinal, de base orgánica, el cual debe ser tenido en 
cuenta por el personal docente. McEwan (1995), además afirma que el trastorno de déficit de atención con o sin hiperactividad, es una condición de base biológica que tiene implicaciones a lo largo de la vida.

Pueyo, et al (2000) manifiesta que al referirse al déficit de atención, se está hablando de dificultad atencional, déficit de la inhibición de respuestas, impulsividad y alteración motora. Scandar (2000, p. 10) señala que "es un síndrome biocomportamental del desarrollo y generalmente crónico, de presentación heterogénea, frecuentemente de origen innato y/o genético en el campo de la atención (inatención), el control de los impulsos (impulsividad) y la regulación del nivel de actividad (hiperactividad)"

Barkley (1997), una de las autoridades en el estudio del trastorno, manifiesta que el verdadero problema del trastorno de déficit de atención con hiperactividad, consiste en la dificultad para inhibir la conducta, o sea, controlar el impulso para responder a una situación. Bauermeister (2000), señala que a través de su práctica profesional y sus investigaciones, ha llegado a la conclusión de que el comportamiento que presentan estas personas, tiene que ver con un rezago en el desarrollo del autocontrol. Lo mismo señala Routh (1980) citado por Kirby y Grimley (1992), al hacer notar que es "la incapacidad constante de un niño para satisfacer, de acuerdo con su edad, exigencias circunstanciales de actividad contenida, atención sostenida, resistencia a distracciones e inhibición de respuestas impulsivas"

Como puede apreciarse, hay variedad de enfoques y propuestas para entender el significado de este trastorno. La selección de características que lo definen, se irá construyendo, poco a poco, en este artículo. La multiplicidad de rasgos, comportamientos y consecuencias es muy amplia, lo que dificulta, en muchas ocasiones, observar en la persona con el trastorno manifestaciones de conductas típicas como sucede con otros trastornos de comportamiento o funcionales. Por este motivo es necesario conocer lo que se está discutiendo teóricamente, como producto de procesos investigativos, para poder tener el referente que permita la comprensión del caso particular a que se pueden enfrentar las personas profesionales en educación o bien los padres y madres.

Hay coincidencia en muchos autores, de que el déficit de atención es una dificultad escondida, no tiene marcas visibles que permitan su fácil registro. Los niños que la tienen se identifican claramente cuando interactúan con otros de su misma edad en tareas organizadas y/o productivas.

La intervención con las personas, particularmente los niños, que presentan comportamientos típicos de este cuadro clínico, se ha hecho en los últimos años desde el abordaje multimodal, entendiendo este como la necesidad de atender integralmente a la 
persona, creando una red social a su alrededor. La importancia de este enfoque que deriva de la óptica ecosistémica, está dada, entre otros aspectos según Scandar (2000, p. 153) "en la necesidad de concurrir a la escuela para explicar a los docentes la situación del paciente... escuchar directamente los problemas que tiene que enfrentar cotidianamente y trazar con ellos las estrategias para enfrentarlos." Es criterio de la autora que el papel que tiene la persona profesional en educación para el desarrollo exitoso de estos niños, es fundamental. De ahí la necesidad de que, al igual que los demás profesionales que intervienen en la atención de estas personas, tenga un sólido y claro conocimiento del trastorno y de la labor pedagógica que debe realizar, para que su aporte, junto con el de otros profesionales sea efectivo para el logro del desarrollo integral de sus alumnos.

En las líneas siguientes, se destacará información relevante para que los docentes y las docentes comprendan las causas y consecuencias, así como las conductas que caracterizan a las personas con déficit de atención y puedan lograr un acercamiento al niño y a la niña por medio de mejores y adecuadas estrategias para cumplir con su trabajo.

Primeramente, se va a presentar una serie de consideraciones referentes al desarrollo histórico del trastorno y posteriormente se discutirán las causas y diversas propuestas que se han diseñado para su comprensión, siempre pensando que hay una cantidad diversa de estudios que pretenden ofrecer explicaciones al respecto, pero no hay ninguna, a nuestro criterio, que ofrezca una explicación completa e integral.

\section{Desarrollo histórico de los trastornos de atención}

Con base en los aportes de García Castaño, 2001; Scandar, 2000; Armstrong, 1997; Armstrong, 2001, entre otros, los trastornos de la atención son mencionados en la literatura, desde hace muchos años y son estudiados desde diferentes enfoques; médico, psicológico y pedagógico. Ya en 1867, se comentan algunas de las características de las personas con trastornos en la atención y, entre los enfoques predominantes de la época se encuentra un escrito de George Still que, al analizar 20 niños, los describe como apasionados, desafiantes, malévolos y sin volición inhibitoria y propone que esto se debe a una lesión cerebral sutil que afectaba el carácter moral de las personas.

En 1934, se enfoca este trastorno desde una perspectiva orgánica y, en la época de los años 40, se habla de la presencia de un síndrome cerebral mínimo. En los 50, de síndrome de impulso hiperquinético; en los 60, de disfunción cerebral mínima y, la persona que la padece es considerada de conducta anormal o patológica y es tratada como un enfermo. En la década de los ochenta, la investigación de estos trastornos atribuye la causa 
probable a anormalidades en la función neurológica, en particular a un trastorno de los procesos neuroquímicos relacionados con las sustancias neurotransmisoras, lo cual se reafirma con la utilización de técnicas de investigación neurológicas cada vez más refinadas. Se ha podido constatar que las personas con déficit atencional, presentan una tasa metabólica menor en el área de la corteza cerebral y se clasifica en el DSM IV, como Trastorno de Déficit Atencional / Hiperactividad, que es la terminología que se utiliza en estos momentos.

\section{Investigaciones epidemiológicas del trastorno}

En estudios epidemiológicos realizados por la Organización Mundial de la Salud y por la Asociación Psiquiátrica Americana, los porcentajes que se señalan como prevalencia, son en Estados Unidos entre un $3 \%$ y un 5\%; en Puerto Rico un 9.5\%; en Canadá un 9\%; en Colombia alrededor de un 16\%; en Nueva Zelanda oscila entre un $2 \%$ y un $6 \%$; en Alemania un $4 \%$ : en China entre un $6 \%$ y un $9 \%$; y en Ucrania un 12.6\%. (Barkley, 1990, citado por García, 2001) Este último autor señala que se debe tener presente que los criterios de evaluación, no fueron siempre los mismos ni fueron aplicados para todas las poblaciones en igual forma. No obstante, para este trabajo, lo que interesa destacar es la incidencia del trastorno. En Costa Rica, aunque no se tienen estudios de este tipo, sí se puede considerar que un alto porcentaje de niños y adolescentes escolares están recibiendo tratamiento médico debido, a la presencia de rasgos y síntomas que conforman el cuadro clínico del trastorno, tal como puede desprenderse de los informes sobre consumo de Ritalina que lleva el Ministerio de Salud. El metilfenidato es el psicoestimulante ${ }^{2}$ más recomendado para la atención médica de estas personas. El metilfenidato es una sustancia que aumenta la capacidad de concentración y autocontrol, según lo propone Barkley (1998), quien manifiesta que los medicamentos incrementan los mecanismos excitatorios del cerebro, a la vez, aumentan aquellos mecanismos responsables de los procesos de inhibición. Esta condición produce un mejoramiento en la concentración, la coordinación motora, y el control de los impulsos.

El déficit de atención con o sin hiperactividad, es un trastorno que permanece de por vida con la persona y que se puede diagnosticar generalmente, cuando el niño inicia la etapa escolar, alrededor de los seis años, aunque algunos de sus signos y síntomas pueden estar presentes desde edades tempranas. Se informa en la literatura que este trastorno se 
manifiesta, tanto en hombres como en mujeres, con una prevalencia significativamente mayor en los primeros. El estudio realizado en 1989 por Szatmari (citado por Scandar, 2000, p. 113), presenta los siguientes resultados:

\begin{tabular}{|l|c|c|}
\hline \multicolumn{3}{|c|}{$\begin{array}{c}\text { Estudio epidemiológico de Szatmari } \\
(\mathbf{1 9 8 9 )}\end{array}$} \\
\hline \multicolumn{1}{|c|}{ Item } & Niños & Niñas \\
\hline$\%$ de la población entre 4 y 6 años con TDAH & $9 \%$ & $3.3 \%$ \\
\hline$\%$ de la población entre 7 y 11 años con TDAH & $10 \%$ & $3.3 \%$ \\
\hline$\%$ de la población entre 12 y 16 años con TDAH & $7.3 \%$ & $3.4 \%$ \\
\hline
\end{tabular}

Como puede apreciarse, los porcentajes en los varones siempre son mayores y tienden a decrecer a partir de la adolescencia, pues se supone que se han desarrollado estrategias que permiten el autocontrol de las conductas típicas de estas personas, aunque no por desaparición de los signos del trastorno. Por su parte, la incidencia en las niñas permanece bastante estable y cada vez con mayor frecuencia la explicación de esto se responde con argumentos de índole sociocultural, tales como los patrones de crianza a que están sometidos los niños y las niñas en nuestra sociedad occidental. Bauermeister (2000, p. 67) reseña un estudio realizado por Isabel Picó, relacionado con el machismo y la educación en Puerto Rico, en donde se les pidió a los maestros, una lista de adjetivos que describieran la conducta que se espera de los niños y las niñas en el salón de clase. Los adjetivos que los maestros escogieron para cada sexo, señalan claramente las diferentes expectativas que se tienen, esto, menciona el Dr. Bauermeister, contribuye a que tanto los maestros como los padres y la sociedad en general, son menos tolerantes con las conductas que caracterizan el déficit de atención con hiperactividad en las niñas y, por tanto, sus conductas son corregidas rápidamente, lo que podría manifestarse en el desarrollo psicológico y social de las niñas.

Las conductas propias del trastorno se siguen presentado en la vida adulta y ocurren en cualquier nivel socioeconómico y cultural. También la investigación señala que afecta a los niños, niñas, adolescentes y adultos de todos los niveles de inteligencia, según manifiesta Barkley (1998).

\footnotetext{
2 Drogas eficaces y seguras bajo supervisión médica especializada, utilizadas por su capacidad para incrementar el alerta del sistema nervioso central.
} 


\section{Conductas de las personas con trastornos de atención}

La característica más sobresaliente de las personas que tienen trastornos de la atención, es que presentan conductas que les perjudican en diferentes áreas de su vida personal, académica y social. La mayoría de estas conductas se manifiesta con una intensidad y frecuencia que los distingue de otros niños, que podrían comportarse de manera similar. Entre las características de estas personas se encuentra la dificultad en la atención propiamente dicha, en cualquiera de los momentos del proceso, sea en el enfoque, la selección, el sostenimiento por la cantidad de tiempo que sea necesario para el cumplimiento de la tarea requerida, la inhibición de estímulos para poder concentrarse en lo que se requiere o, bien, el poder cambiar el foco de atención, cuando el contexto así lo requiera. También se encuentran marcadas conductas relacionadas con la impulsividad, tanto en el nivel de comportamiento, como en el nivel cognitivo $y$, por último, la hiperactividad que provoca conductas de desasosiego, inquietud, movimientos constantes, entre otras.

Como puede deducirse de lo anterior, las personas que presentan estos trastornos, particularmente los niños y adolescentes que asisten a los centros educativos, presentan dificultades para comportarse y recibir adecuadamente los estímulos para que el proceso de enseñanza - aprendizaje sea eficiente, eficaz y efectivo. Por diversas razones, algunas personas no desarrollan, en el nivel esperado para la edad que tienen, habilidades y destrezas para sostener la atención por un tiempo determinado, no logran inhibir los impulsos y tampoco pueden regular con eficiencia, la actividad física.

Es grande el esfuerzo que realizan estos niños y jóvenes y escasos los resultados que obtienen, con un deterioro progresivo de su autoestima, cuando los trastornos no son atendidos integralmente. Asimismo, se reportan serias dificultades en el mantenimiento y disfrute de las relaciones interpersonales, las cuales se ven marcadas por las constantes transgresiones a las normas debido a la impulsividad, a la falta de atención a las mismas y a sus procedimientos y a la necesidad de movimiento constante, según lo reportan entre otros, Bauermeister, 2000; Scandar, 2000; Barkley, 1998; INMH, 2001; Sosin y Sosin, 2001; American Academy of Child \& Adolescent Psychiatry s.f., y Fowler, 1995.

Como se mencionó, el proceso de enseñanza - aprendizaje de estos niños, se ve alterado por los factores antes mencionados, por lo que es necesario operacionalizar lo que se entiende por atención, impulsividad e hiperactividad, a saber:

- La atención: en ella se involucra una serie de habilidades, tales como poder hacer un adecuado enfoque de los estímulos relevantes, la selección del estímulo correcto que debe enfocar, el sostener por un periodo determinado la atención sobre el estímulo 
enfocado, el poder inhibir otros estímulos y la capacidad de cambiar de estímulo al completar una tarea e iniciar otra. Una de las características de estos niños, es que la dificultad de atención se empieza a manifestar desde pequeños de una manera intensa y persistente. (Añaños, 2001; Scandar, 2000; Bauermeister, 2000; Boujon, y Quaireau 1999; Kirby y Grimley, 1992).

- La impulsividad: puede ser separada en dos rangos; en el nivel cognitivo cuando las dificultades se presentan para detenerse, pensar y razonar ante una determinada situación y, en el nivel del comportamiento, que se refiere sobretodo a la incapacidad para inhibir una conducta determinada o evitar una respuesta verbal o de acción. Lo que se manifiesta en los niños y en los adolescentes con déficit de atención, es que con la edad no parecen desarrollar las habilidades para autorregular el comportamiento, según lo esperado en las personas conforme van desarrollándose (Bauermeister, 2000; Scandar, 2000; García, 2001).

- La hiperactividad: no siempre está presente en las personas con trastornos de la atención. En algunas ocasiones, se encuentran niños que manifiestan trastornos de la atención que no están acompañados de conductas hiperactivas. Una gran mayoría se muestra excesivamente inquieta. El nivel de inquietud puede variar dependiendo de la situación en que se encuentren, y del grado de interés que la actividad en sí tenga para él. No obstante, en estos niños y adolescentes, se distingue su necesidad de estar en movimiento constante. En otras ocasiones, presentan conductas motoras gruesas (por ejemplo pararse y caminar por el aula, cuando debe estar sentado). En otras, los movimientos son realizados con los músculos finos (por ejemplo tamborilear sobre el pupitre). También presentan, asociadas al movimiento, conductas de "hablar solos", jugar con los objetos que tienen delante, tocar lo que le rodea, etc. García (2001, p. 21) llama la atención al decir que el simple movimiento de un niño no puede ser catalogado, como déficit de atención, por el contrario lo que debe ser indicador de hiperactividad es que "se trata de movimientos que no tienen ningún propósito y que se dan en circunstancias inapropiadas... Son movimientos que se dan... porque sí. Al niño se le hace difícil controlarlos...". (Bauermeister, 2000; Scandar, 2000; García, 2001).

Las preguntas que siguen a lo anterior son: ¿Qué causa el déficit de atención con o sin hiperactividad? ¿Cómo se caracteriza? ¿Cuáles son las principales consecuencias que tienen para la persona y para los procesos escolares? 


\section{Causas de los trastornos de atención con o sin hiperactividad.}

Respecto a las causas, como se mencionó líneas arriba, hay una serie de propuestas; muchas de ellas con fundamento teórico y otras cuyas explicaciones no se han podido comprobar con claridad científica. En lo que sí está de acuerdo la mayoría de los estudiosos y la autora con ellos, es que el déficit de atención con o sin hiperactividad, es un trastorno variado y que no hay dos personas que lo manifiesten de igual forma. Es imposible, dada la variedad de conductas y factores asociados, tratar de explicar el trastorno a partir de una única causa. La investigación ha arrojado evidencia para identificar algunas posibles causas $y$, particularmente, ha señalado algunos factores de riesgo que podrían desencadenar las manifestaciones del trastorno. Este enfoque de riesgo, propuesto por Bauermeister (2000), ha sido adoptado en este artículo por cuanto permite a una persona profesional en educación, visualizar la gran cantidad de factores asociados al comportamiento de los niños dentro de su aula, para lograr, por tanto, comprender la gama de manifestaciones y la variabilidad en la presencia de las conductas que tiene el mismo niño en un día, semana o período y ante determinadas situaciones.

Con el fin de que los docentes conozcan de dónde se originan muchas de las explicaciones y que muchos profesionales en nuestro país utilizan como referente, haremos una breve descripción de ellas, siguiendo la propuesta que hace Bauermeister (2000), enriquecida por Barkley (1998), Scandar (2000), Gratch (2001), Mediavilla-García (2003), y Armstrong (2001), entre otros.

\section{a) Influencias neurobiológicas:}

Se refieren a una serie de factores de origen neurológico y de origen biológico cuya evidencia ha sido determinada en varios estudios. Entre estos factores tenemos:

\section{- Influencias hereditarias}

Los estudios apoyan con cierta consistencia la hipótesis de que en algunas familias la predisposición, particularmente del déficit de atención con hiperactividad es heredada. Se ha informado, por ejemplo, de que existe una probabilidad entre el 10 y el $35 \%$ de que familiares cercanos al niño también, presentan esta condición.

- Complicaciones antes o durante el parto

Ha sido reportado por muchas madres, que el embarazo o el parto ha sido especialmente complicado, en el caso del nacimiento del niño con déficit de atención. Entre las complicaciones más comunes están las relacionadas con infecciones por toxinas, presión alta, retención de líquidos, partos prolongados o muy cortos, nacimiento prematuro o un 
peso bajo al nacer. No obstante, a pesar de estos reportes, no se ha podido establecer una evidencia contundente de qué el tipo de complicación haya causado dificultades en el nivel cerebral que pueda causar el déficit de la atención. Aún en los casos que se han reportado estas alteraciones, no todos los niños que las han vivido, han desarrollado el déficit de la atención, lo que lleva a pensar en el peso que el ambiente tiene para el desarrollo del trastorno.

- Desbalance o deficiencia química:

Algunos estudios señalan que un desbalance o deficiencia en el cerebro de algunas sustancias químicas, llamadas neurotransmisores, puede causar las dificultades de atención y concentración, así como el descontrol de los movimientos en los niños con déficit de atención. Los neurotransmisores cumplen con la tarea de transmitir mensajes de una célula a otra, por lo que una deficiencia puede alterar el funcionamiento de la parte cerebral afectada. En el caso de este trastorno, los neurotransmisores asociados, particularmente con la hiperactividad, son la dopamina y la norepinefrina. Esta explicación se fortalece, cuando se estudia el efecto de las sustancias estimulantes que se usan frecuentemente en el tratamiento de las personas con el trastorno, pues cumplen el efecto de aumentar la concentración de aquellos neurotransmisores que tienen la función de controlar los procesos de regulación de la actividad y de sostener la atención. La dopamina tiene el efecto de inhibir la actividad de las neuronas, particularmente, las que están implicadas en las emociones y en el movimiento.

- Circulación sanguínea y actividad metabólica en el cerebro

El desarrollo de técnicas que han permitido analizar el flujo de sangre y la actividad metabólica en diferentes áreas del cerebro, indica que el cerebro de las personas con déficit de atención e hiperactividad tiende a presentar un nivel más bajo de circulación o metabolismo en las áreas frontales y otras estructuras cerebrales que están interconectadas con el área frontal. Estas regiones cerebrales son precisamente las que cumplen un papel importante en la inhibición del comportamiento y en las habilidades para sostener la atención.

- Estructura del cerebro

En el Instituto Nacional de Salud Mental de los Estados Unidos (2001), se han realizado estudios por medio de la resonancia magnética y se ha explorado el tamaño de diversas estructuras cerebrales. Estas investigaciones hallaron que el cerebro de los niños que presentan el trastorno de déficit de atención con hiperactividad, tienen su lóbulo frontal 
anterior y otras estructuras relacionadas, particularmente, las ubicadas en el lado derecho, más pequeñas.

Bauermeister (2000) y Scandar (2000), plantean que es necesario tener algunas consideraciones, respecto a las influencias neurobiológicas en el trastorno del déficit de atención. Entre ellas la ausencia de un daño cerebral en los niños, jóvenes o adultos que presentan el trastorno, y la falta de evidencia de que la estructura del cerebro esté dañada. Por otro lado, el diagnóstico del trastorno no puede ser realizado, a partir de la presencia de estos factores. Se necesitan otros requisitos y procedimientos para señalar que se está en presencia de una persona con déficit de la atención con o sin hiperactividad. Asimismo, coinciden éstos y otros autores en señalar que los rasgos heredados pueden estar presentes en todas las personas y lo que se va a encontrar, son variaciones en la tendencia con que se manifiestan. Así algunas personas pueden presentarlos leve o tenuemente y otras hacerlo con mayor intensidad. Tampoco, se señala que, se puede establecer un diagnóstico de déficit de atención, solamente porque están presentes las influencias neurobiológicas señaladas líneas arriba, pues el funcionamiento y desarrollo de una persona responden siempre al principio de las diferencias individuales, y no pueden ser explicados a partir de una sola causa. Para este caso en particular, la influencia del ambiente es también un factor de mucho peso, como veremos a continuación.

\section{b) Influencias ambientales:}

En este apartado, se han tratado de organizar aquellas causas que cuentan con alguna evidencia científica y tienen relación con factores ambientales. Entre estas influencias están:

- El ambiente social y cultural

Las manifestaciones, particularmente las que se relacionan con la movilidad o la impulsividad, tienen una respuesta sociocultural. En varios estudios, se ha señalado que hay diferencias en la forma como las personas se comunican y viven cotidianamente. Por ejemplo, hay diferencias entre la cultura anglosajona y la hispana; a esto hace referencia el estudio realizado por la Dra. Nine Curt (citada por Bauermeister 2000:65), en donde señala que la cultura hispana tiene más manifestaciones físicas y de movimiento al momento de interactuar: muchos gestos, expresiones faciales, espacios interpersonales más cercanos, mayor cantidad de contacto físico, etc., y que llevan al Dr. Bauermeister a proponer que el déficit de atención con hiperactividad, puede ser mejor tolerado en la cultura hispana que en otras que tienen menores rasgos de expresividad en las 
relaciones sociales. En esta misma línea explicativa, está lo señalado anteriormente para explicar las diferencias de prevalencia del trastorno entre los niños y las niñas.

- Ambiente familiar

Aquellos niños que viven en familias que no tienen la estructura o la estabilidad para que se produzca el aprendizaje de los patrones de conducta necesarios para poder prestar atención, autorregular la conducta y el nivel de actividad, de acuerdo con el espacio y el lugar donde se esté, tienen mayor riesgo de desarrollar los signos del trastorno. La historia de la familia, las relaciones intrafamiliares y el estado emocional de los padres y, en especial de la madre, pueden ser factores de riesgo, cuando no son funcionalmente los adecuados. La presencia de una estructura familiar muy rígida, que manifieste poco afecto y comprensión a las necesidades de los niños o con una sobreprotección por parte de las figuras significativas, pueden también ser factores que faciliten el desarrollo del trastorno. Sin embargo, es necesario mencionar que no todos los niños que viven en una familia con estas condiciones desarrollan el déficit de atención. Asimismo, muchos niños que lo tienen no viven en esas condiciones.

- Ambiente escolar

Las condiciones de los centros educativos, el clima organizacional del mismo, la personalidad del profesional en educación, el desarrollo del currículo y los aspectos metodológicos y didácticos ofrecen un peso muy importante en la agudización de las manifestaciones de las conductas propias del trastorno. Los espacios limitados, las distracciones ambientales, tales como ruidos, poca iluminación, asientos inadecuados, demandas académicas muy altas o muy bajas, currículo poco significativo y técnicas de enseñanza aburridas o monótonas, son solo algunas de las condiciones que pueden incrementar la presencia y manifestación de los rasgos característicos del trastorno.

- Desventaja económica.

Los autores consideran que criarse en ambientes de desventaja social y económica, es un factor de riesgo importante para el desarrollo de las características del déficit de atención. Aunque por sí misma no es sinónimo de presencia del trastorno, pues hay niños de otros substratos económicos que tienen este diagnóstico. Desde el enfoque de riesgo, se puede mencionar que asociadas a esta condición, se encuentran otras como la deficiencia en el cuido parental, las dificultades de atención médica, la permanencia del niño en el centro educativo, la falta de apoyo para el desarrollo de habilidades sociales, lo que sin lugar a dudas, es una condición que podría facilitar el desarrollo del déficit de atención. 


\section{- Venenos ambientales}

Se ha encontrado cierta asociación entre los niveles elevados de plomo en la sangre, la inatención y la hiperactividad. Se señalan las dificultades para aprender que tienen los niños en esta condición, por lo que podría aceptarse que esta situación, junto con la exposición al humo del cigarrillo, el alcohol o las drogas utilizadas durante el embarazo, pueden contribuir al desarrollo del trastorno, aunque posiblemente en menor grado que otras señaladas anteriormente.

Se desea enfatizar que el medio en que el niño se desenvuelve, es determinante para la forma, frecuencia e intensidad con que se manifiesten las conductas propias del trastorno. Considera la autora que si un niño ha tenido un cálido, comprensivo y consistente ambiente familiar y escolar; si hay límites que le ayuden a desarrollar habilidades sociales y a autorregular su conducta; si hay apoyo y cuido de su autoestima; si hay una clara tendencia hacia la atención integral, entonces es probable que el niño pueda funcionar y desarrollarse con mayores posibilidades de éxito.

\section{c) Influencias sin apoyo científico}

Debido a que circula en el medio una serie de creencias con respecto a las causas del trastorno, se considera oportuno señalar que los factores asociados a la alimentación, alergias, vitaminas y minerales no tienen evidencia científica de ser causantes o factores influyentes para el desarrollo del trastorno. Asimismo, está desechada la vieja idea de que existe un daño en el nivel del cerebro y que es un disturbio emocional severo el que provoca la presencia de los síntomas y signos propios del trastorno.

No se quiere terminar el apartado de las causas, sin antes señalar, que dada la cantidad de factores que inciden en la presencia del trastorno, la investigación continua es fundamental para ir aclarando posibilidades y ojalá en algún momento, se puedan, determinar con mayor precisión, los precipitantes fundamentales de este trastorno.

\section{Consecuencias del trastorno}

Al analizar las implicaciones que tiene en las personas el trastorno del déficit de atención, es importante mencionar que éstas pueden organizarse para efectos del presente trabajo en tres grandes áreas; aquellas relacionadas con el desarrollo emocional de las personas; las relacionadas con el desarrollo social, particularmente, en cuanto a las relaciones interpersonales y aquellas relacionadas con la vida académica. Las tres son 
fundamentales para el desarrollo integral de los niños y los adolescentes y para el éxito en el medio escolar.

\section{a) Desarrollo emocional de las personas con trastornos de la atención.}

La mayoría de los autores consultados y, entre ellos, algunos que se reseñan líneas abajo, coinciden en que a lo largo de los primeros años de la vida escolar de las personas con trastornos en la atención, es necesario cuidar estratégicamente los aspectos de índole emocional.

La autoestima es un aspecto central en el desarrollo de estos niños y de cualquier ser humano. La misma afecta todas las áreas de la vida de una persona, los pensamientos, las creencias, las expectativas, así como los sentimientos pueden dar una evaluación y una valoración personal positiva o negativa y, a partir de ahí, cada uno construye la imagen y el concepto sobre sí mismo. La autoestima alta posibilita la productividad; la sensación de sentirse capaz de cumplir con las demandas del medio en que se esté; permite cumplir eficientemente con las tareas que enfrenta; puede apreciar los logros alcanzados y puede visualizar las metas personales o que el medio ha planteado.

Al respecto como señala Papalia, et al (2001, p. 550):

(...) es en la niñez intermedia cuando los juicios de valor sobre sí mismos se vuelven más reales, equilibrados y completos, y los expresan con más claridad. La autoestima es un componente importante del autoconcepto, que relaciona los aspectos cognoscitivo, emocional y social de la personalidad. Los niños con una autoestima alta tienden a ser alegres, mientras que quienes tienen una autoestima baja tienden a ser depresivos.

Como se desprende de la cita anterior, el proceso psicológico relacionado con el conocimiento de sí mismo, tiene estrecha relación con la propuesta de Eric Erikson (citado por Papalia, et al, 2001, p. 551) para la etapa de la niñez en el ciclo evolutivo. Erikson plantea que el niño debe resolver su cuarta crisis de desarrollo, denominada laboriosidad versus inferioridad, en donde para una adecuada resolución de la misma, el papel de la autoestima es determinante. El desarrollo del sentimiento de competencia que no es otra cosa que el sentirse capaz de dominar destrezas y realizar tareas, es propio de esta edad y es reafirmado por la respuesta social que da el medio. Se puede leer en el texto antes señalado "la cuarta etapa alternativa del desarrollo psicosocial, que se presenta durante la 
niñez intermedia donde los niños aprenden las destrezas productivas que su cultura requiere, pues de otra manera enfrentarán sentimientos de inferioridad"

Si tomamos esa realidad del desarrollo integral de los niños y la analizamos con la realidad de los niños con trastornos de la atención, encontramos que la mayoría de ellos no tiene dificultades cognoscitivas para resolver las tareas propias de la demanda del medio escolar. Poseen algunas de las destrezas básicas para dar un rendimiento académico aceptable y tienen el sentimiento de que "pueden" hacer las cosas, no obstante, la respuesta del medio social le reafirma que, a pesar de esas condiciones, su participación no es la adecuada y, en la mayoría de las ocasiones la referencia es más bien que "no es la esperada".

Esto causa gran confusión en los niños, por un lado, saben que en muchas ocasiones "da la talla", pero ellos son las primeras que se desorientan cuando esa "talla" no es consistente y constante como lo está pidiendo el medio, especialmente el escolar.

Estos estudiantes demandan de la persona profesional en educación y de los padres y madres, "colocarse en sus zapatos", como propone el Dr. Bauermeister (2000) refiriéndose a la propuesta de Brooks, desarrollar acciones de empatía y comprensión sobre las respuestas que ofrece a partir de las dificultades que está teniendo con su autoestima. Son alumnos que pueden presentar conductas inadecuadas, como una forma de canalizar el dolor que sienten al fracasar, a la humillación de no poder responder, como se espera de ellos y, particularmente, al desprecio o rechazo de sus iguales y otros adultos significativos en su vida. Es necesario tener presente que estas conductas no son conscientes en el niño. Reafirma el Dr. Brooks en la misma fuente citada, que "el hecho de que utilizan estrategias defensivas ineficientes y criticables no debe hacernos olvidar la angustia presente en ellos" (Bauermeister, 2000; 101).

Robert Brooks (1991, en Bauermeister, 2000, p. 98), señala que "la autoestima... es una fuerza poderosa que ayuda a las personas a resistir y sobreponerse a situaciones difíciles en la vida". Para el caso que nos ocupa, es evidente la necesidad de atender y cuidar todo aquello que tiene relación con la autoestima de los niños con este trastorno. Además de la importancia que tiene para el desarrollo aprendido del autocontrol (recordamos que en este caso, no se desarrolla como producto de los procesos de maduración como en otros niños, sino que debe ser enseñado y aprendido en el medio), es importante para aprender del acierto y del error.

La autoestima y el desarrollo de la misma dependen de una multitud de factores, en una relación dinámica entre el medio (familia, escuela, comunidad, cultura) y los propios de 
la persona (personalidad, temperamento, carácter). Por lo que la atención de la misma no es sencilla en el caso que nos ocupa. Los niños diagnosticados con trastornos de la atención con o sin hiperactividad, desean participar activamente en la escuela; hacer las tareas en el tiempo previsto; cumplir a cabalidad con lo que se espera que hagan, pero no pueden hacerlo. No es que no quieran hacerlo; esta premisa se encuentra en la mente de muchos docentes, padres y madres, según la literatura y los testimonios de muchas personas.

Se hace necesario, entonces, en un programa de atención a estas personas, crear y desarrollar acciones que les permitan reafirmar su autoestima. Son personas con muchas cualidades positivas. Rief (1998), propone una lista de características positivas asociadas, a menudo, con las personas con déficit de atención; entre las que se destacan la facilidad de palabra, la espontaneidad, la creatividad, la calidez, la resiliencia, la sensibilidad de las necesidades ajenas, el buen corazón, la tendencia a ser sociables, el sentido del humor, el realismo, la capacidad para encontrar nuevas soluciones a las cosas. Todas estas características son ignoradas o no valoradas positivamente en un medio educativo tradicional, centrado en el desarrollo de contenidos e información y no en el desarrollo de la persona.

Los docentes, los padres y las madres, pueden proporcionar situaciones para que los niños con trastornos de la atención desarrollen el sentido de la responsabilidad; la posibilidad de ayudar a los demás; espacios para reflexionar sobre las dificultades; estrategias para tomar decisiones y resolver problemas; manejo de la frustración, el enojo, la cólera y la ira ante el fracaso y, por supuesto, la actitud y el modelaje sobre el hecho de que el error no es sinónimo de fracaso ( $y$ castigo), sino fuente de aprendizaje; facilitarle espacios para que puedan demostrar sus habilidades y enseñarle a disfrutarlas. (Papalia, et.al. 2001; Bauermeister, 2000; Shapiro, 1997; Clemes, et al. 1988)

Como lo señalan García y Magaz (2001, p. 27)

como consecuencia de la acumulación crónica de frustraciones y castigos, éstos en su mayor parte dirigidos a su persona y no sólo a su comportamiento inadecuado, el niño/a con TDAH suele llegar a la preadolescencia con un autoconcepto de sí mismo/a muy malo y una autoestima escasa.

\section{b) Desarrollo social de las personas con trastornos de la atención.}

Otra de las áreas que ofrecen mayores dificultades para el desarrollo integral de las personas con trastornos de la atención, es la de las relaciones sociales, particularmente en el apartado de las relaciones interpersonales con los iguales. 
Shapiro (1997, p. 159) se manifiesta, dirigiéndose a los padres y madres, pero que para efectos de este artículo consideramos por su fondo que es muy útil señalarlo también para las personas profesionales en educación o que laboran en el medio educativo:

De todas las capacidades del $\mathrm{CE}^{3}$ que desarrollará su hijo, la de llevarse bien con los demás es la que contribuirá más a su sentido de éxito y de satisfacción en la vida. Para desempeñarse efectivamente en un mundo social, su hijo necesita aprender a reconocer, interpretar y responder en forma apropiada a las situaciones sociales. Debe juzgar la forma de conciliar sus necesidades y expectativas con las de los demás.

Estas capacidades sociales, dadas por los procesos de socialización, requieren fundamentalmente del autocontrol que favorece la convivencia y, la falta de éste, es uno de los puntos centrales del trastorno de atención. Por lo que es obvio pensar que estos niños desde pequeños, empiezan a padecer las consecuencias de su falta de control. Se les dificulta seguir instrucciones; acatar reglas como levantar la mano antes de hablar; seguir las normas de un juego; esperar turno; atender tareas que requieren sostener o mantener la atención con persistencia y algún esfuerzo. Responden impulsivamente y actúan de igual manera; tienen dificultad para controlar la satisfacción de sus necesidades en aras de las necesidades del grupo, etc. La respuesta de sus pares, así como de los adultos (padres, madres, abuelos, tíos, docentes) no se hacen esperar: el rechazo o la incomodidad se ponen de manifiesto, a pesar de que se les quiere mucho. Cualquier niño en las edades tempranas, es sensible a la interacción con los demás. De ahí que la ausencia de comprensión de él mismo sobre lo que le pasa, afecta su desarrollo socioemocional; lesiona la autoestima y puede generar conductas de agresión, culpa, rebeldía y todas aquellas asociadas a la falta de disciplina, si se refiere a la participación del niño en un centro educativo.

Igualmente los adolescentes en cualquiera de sus etapas, enfrentan dificultades en sus relaciones interpersonales y en el manejo de la imagen de sí mismos, el autoconcepto y la autoestima. Aunque no es el objetivo de este artículo, las mismas características pueden encontrarse en las personas adultas que no han tenido oportunidad de atender los signos y síntomas de este trastorno.

En lo social, particularmente en las relaciones de grupo, la frustración en las relaciones interpersonales acompañadas generalmente de reacciones de burla, rechazo, falta de cooperación, críticas, hacen que la vida social sea más limitada que la de otros niños. En

\footnotetext{
${ }^{3} \mathrm{CE}$ es la abreviatura de Coeficiente Emocional
} 
ocasiones, se llevan mejor con niños o niñas más pequeñas en edad, que él. Para la vida de un niño o una niña, el aspecto social es de especial cuidado como manifiesta Shapiro (1997, p. 187): "Después de que un niño aprendió a hacerse amigos individuales, la capacidad de unirse a un grupo de pares del mismo sexo es el segundo pilar que necesita para crear relaciones sociales sólidas". La sensación de no pertenencia es una de las características que suelen reportar los niños y las niñas que tienen trastornos de la atención, la impulsividad y la hiperactividad. La frustración en las relaciones sociales provoca aislamiento, pérdida de amistades y críticas en la familia y de parte de los y las docentes.

Papalia, et al (2001, p. 572), refiriéndose a las relaciones interpersonales en el grupo de iguales de los niños en edad escolar, señala que "... no es sino hasta la niñez intermedia que el grupo de compañeros tiene su propia razón de ser. Los grupos se conforman de manera natural entre los niños que viven cerca o que van a la misma escuela...". Para este trabajo se considera que uno de los beneficios que recibe el niño, al participar con sus iguales, se centra en el desarrollo de las destrezas necesarias para su socialización y para intimar con otras personas, así como para alcanzar su sentido de pertenencia. Otro aspecto importante es la capacidad de realizar juicios, poner a prueba valores y crear las condiciones para, posteriormente en la adolescencia, tomar decisiones sobre cuáles valores mantener y cuáles confrontar.

Para pertenecer a un grupo de iguales, el niño debe cumplir con ciertos procesos, entre ellos el aceptar las normas, valores y comportamientos que rigen las relaciones interpersonales en el grupo, llámese grupo de amigos o compañeros de aula. Solo así se puede funcionar grupalmente $y$, desde esta óptica, el niño con trastornos de la atención, debido a su impulsividad para hablar y para actuar, tiene serias dificultades para mantener su aceptación en el grupo, no así su ingreso al mismo, pues como mencionamos anteriormente, tiene muchas cualidades que le abren espacios de participación, pero dificultad para mantenerse en ellos, debido a su conducta.

Siguiendo a Shapiro (1997), en su propuesta sobre el desarrollo de las habilidades sociales, encontramos que los criterios que él utiliza, a saber: la capacidad de conversar; la importancia del humor y de las situaciones placenteras; la capacidad de hacer amigos; la capacidad para funcionar en un grupo, y los modales de comportamiento. Estos criterios tienen como punto de partida esencial, la capacidad de autocontrol, espera, tolerancia, empatía y respeto. Estas características son de difícil manejo para los niños y niñas con trastorno de la atención, no porque no tengan la capacidad de manifestarlas, sino porque esa manifestación es impredecible y fluctuante, lo que desconcierta a los demás. 
La necesidad de atender el desarrollo de habilidades sociales, es tan importante, como la atención de la autoestima señalada anteriormente. Dice Shapiro (1997, p. 161) que "cientos de estudios muestran que el rechazo de los pares en la niñez contribuye a un desempeño académico deficiente, problemas emocionales y un mayor riesgo de caer en la delincuencia en la adolescencia"

Scandar (2000, pp. 69-70) al referirse a las pobres habilidades interpersonales y sociales de estas personas, manifiesta que no forman parte del cuadro diagnóstico, porque no son de utilidad para establecer diferencias, lo cual puede explicar por qué, en muchos casos, no son consideradas por los especialistas en el momento de establecer recomendaciones. No obstante, señala el autor,

(...) las dificultades que los niños con $\mathrm{TDAH}^{4}$ tienen en esta área son casi siempre importantes, al grado de convertirse en uno de los ítems básicos a tomar en cuenta. Ya sea que el niño con TDAH sea subtipo agresivo y/o del subtipo ansioso, tendrá problemas en la esfera interpersonal. Algunas dificultades serán coincidentes, el rechazo que puede sufrir del medio social por ejemplo, pero la mayoría son divergentes.

Varios estudiosos de los trastornos de la atención, coinciden en que algunas de las características presentes tienen las mayores dificultades, entre las que cabe señalar:

- Reacciones emocionales intensas y exageradas cuando, no pueden lograr el resultado que desean en lo que se proponen socialmente (Scandar, 2000).

- Baja tolerancia a la frustración en situaciones de interacción básica; como por ejemplo, esperar turno para ingresar a un juego de un deporte colectivo; esperar turno para hablar en clase, o bien interrumpir al compañero (Scandar, 2000).

- Seguimiento de instrucciones para el cumplimiento de normas; para llevar a cabo sus propios planes e, incluso, para actuar de acuerdo con los principios legales y morales (García y Magaz, 2001; García C, 2001).

- Molestia a los demás, por lo que suelen recibir un elevado número de recriminaciones verbales y gestuales. En muchas ocasiones recibe castigos físicos (García y Magaz, 2001).

${ }^{4}$ TDAH son las siglas de Trastorno de Déficit de Atención con Hiperactividad 
- Dificultades para establecer y conservar amistades (García y Magaz, 2001; Bauermeister, 2000).

- Rechazo de parte de sus iguales, en parte porque siempre quieren imponer sus normas y criterios, asimismo, no es muy apreciado por sus profesores, por las dificultades que presentan en el desarrollo, por ejemplo, de una explicación (García y Magaz, 2001; Bauermeister, 2000).

- Agresividad y/o retraimiento (Scandar, 2000; Bauermeister, 2000).

- Déficit en la resolución de problemas interpersonales (Scandar, 2000).

- Pautas de comportamiento egocéntricas, hasta egoístas (Scandar, 2000).

- Piensa en él y en la satisfacción inmediata de sus deseos. Los deseos de los demás quedan constantemente en el segundo plano (Gratch, 2000).

Así podrían seguirse señalando aspectos de la interacción social que causan dificultades para las personas con trastornos de atención. Incluso la comprobada impulsividad cognitiva o precipitación que tienen en el nivel del pensamiento, los hace vulnerables a la hora, por ejemplo, de jugar, pues es fácil ganarles por este motivo. Son niños que no piensan las cosas dos veces antes de actuar. No prevén e, incluso, contestan a las preguntas, antes de que se las formulen por completo, o realizan la acción del juego antes de que les toque el turno.

El aula y el centro educativo no son ajenos a estos comportamientos. El rechazo en los juegos, trabajos de grupo y actividades que requieren la actitud colaborativa, pueden ser causa de enfrentamiento entre los niños, debido al manejo de las características antes señaladas. Nadie quiere trabajar con el que puede en cualquier momento, por su comportamiento poco reflexivo, dar el traste con el esfuerzo grupal. Tampoco quieren compartir sus juegos o juguetes, pues la posibilidad de que se rompan o extravíen, aumenta con la participación de ellos. Son señalados y recriminados constantemente por no incorporar las normas de convivencia social en el aula, al manifestar conductas de hablar; responder sin que se le dé la palabra; hablar sin esperar turno; dejar las cosas sin terminar o ni siquiera empezarlas en el tiempo previsto para su conclusión, lo cual se acompaña de una constante intervención del maestro o la maestra o bien del padre o la madre, en el caso de sus tareas. 


\section{c) Aspectos relacionados con la vida académica de las personas con trastornos de la atención.}

Al abordar esta área de la vida de las personas con trastornos de la atención, lo primero que se quiere señalar es lo que propone Scandar (2000b, p. 16), en su artículo TDAH va a la escuela, “... sabemos que un niño con TDAH y de igual capacidad intelectual que otro niño, tiene más probabilidades de fracasar en la escuela ya que es usual verificar un rendimiento académico crónicamente por debajo de sus posibilidades"

Gratch (2001) y Bauermeister (2000), entre otros, hacen hincapié en que la dificultad de estos estudiantes para concentrarse y para mantener bajo control sus impulsos, tiene una relación directa con el rendimiento académico; aspectos con los que se coincide la autora.

Para rendir y cumplir adecuadamente en la escuela, es necesario concentrarse largo tiempo en la actividad, aún cuando en el ambiente exista cantidad de estímulos que pueden provocar distracciones. Esta es la típica situación de un aula regular, donde existe además de los consabidos estímulos ambientales, una cantidad de personas que tienen intereses y formas de trabajo particulares y que se convierten, en última instancia, en estímulos que el cerebro debe inhibir para poder responder únicamente a aquellos que requieran un enfoque de atención para completar la propuesta de trabajo.

Barkley (1998) ha postulado que la dificultad en la inhibición de los impulsos, impide que los diversos procesos psicológicos puedan funcionar eficientemente. Estos procesos psicológicos se denominan funciones ejecutivas. Las funciones ejecutivas según Bauermeister (2001, p. 12 y 2003, p. 1) son actividades mentales de funcionamiento complejo y necesario para acciones como: planificar, organizar, guiar, revisar, regularizar y evaluar el comportamiento necesario para alcanzar metas. Señala que:

... estas funciones empiezan a desarrollarse a partir del primer año de vida y continúan desarrollándose hasta la adolescencia. Por medio de ellas, por ejemplo, podemos responder más a un plan que a las actividades que distraen. Las funciones ejecutivas permiten guiar nuestras acciones más por las instrucciones que nos damos a nosotros mismos que por influencias externas. Es decir, estas funciones permiten autorregular el comportamiento para poder hacer lo que nos proponemos hacer. (Bauermeister 2001, p. 12)

Pineda (2000, p. 1) en su artículo referente a la función ejecutiva y sus trastornos, menciona que éstas vienen a ser una serie de factores organizadores y ordenadores que Volumen 6, Número 1, Año 2006, ISSN 1409-4703 
están en la base o que subyacen a todas las actividades cognoscitivas. Son requisitos indispensables para que estas actividades se puedan llevar a cabo de manera adecuada y con eficiencia. Define el concepto como:

...un conjunto de habilidades cognoscitivas que permiten la anticipación y el establecimiento de metas, el diseño de planes y programas, el inicio de las actividades y de las operaciones mentales, la autorregulación y la monitorización de las tareas, la selección precisa de los comportamientos y las conductas, la flexibilidad en el trabajo cognoscitivo y su organización en el tiempo y en el espacio.

En la página de internet de la Fundación Trastorno de Déficit de Atención con o sin Hiperactividad de Argentina, se plantea que en la actualidad, el DMS-IV no necesariamente incluye todos los síntomas y características de las personas con déficit de atención, pues hay aspectos que no se toman en cuenta y que perfilan cada vez más un acercamiento a la comprensión de estos trastornos. Citando a Denckla, 1996 (2002, p. 1) señalan que:

... las funciones ejecutivas son procesos de control que involucran capacidad inhibitoria, demora en el tiempo de respuesta que posibilite al individuo iniciar, mantener, detener y cambiar sus procesos mentales para lo cual debe establecer prioridades, organizarse y poner en práctica una estrategia.

Para fines de comprensión de los trastornos de atención, el déficit en las funciones ejecutivas explica la heterogeneidad del trastorno, permitiendo un punto de unificación y evidencia la tendencia, cada vez más aceptada, de que el Trastorno por Déficit de Atención responde menos a un déficit en la atención y más a un trastorno deficitario del control de la inhibición.

Es necesario llamar la atención, en este momento, que en los niños con déficit de atención, estas funciones están presentes, o sea, no hay carencia de ellas, pero su funcionamiento no es eficiente, como mencionamos líneas arriba, y esta puede ser la razón por la cual, el funcionamiento del niño en todos los ámbitos y particularmente en el medio escolar, está por un lado sometido a variaciones frecuentes que dificultan la obtención de un rendimiento estable, previsible $u$ homogéneo en el trabajo cotidiano y en las evaluaciones $y$, por otro lado, un comportamiento predecible frente a la tarea por desarrollar.

En este último caso, la guía de las acciones no se manifiesta debido, entre otras cosas, a que el niño con déficit de atención no responde a un plan, sino que cualquier actividad o 
estímulo lo distrae. Esto causa la desorientación en el adulto, sobre todo, cuando el niño carece de un adecuado diagnóstico, pues al conocimiento intuitivo y muchas veces, comprobado que tiene el maestro sobre la capacidad particular del niño, no le corresponde el resultado inestable, demostrado tanto al nivel de rendimiento, como de comportamiento.

Para mantener un comportamiento y un rendimiento estable en las tareas, se requieren procesos de control que involucren la capacidad inhibitoria, la demora en el tiempo de respuesta que posibilite al individuo iniciar, mantener, detener y cambiar los procedimientos mentales para lo cual debe establecer prioridades, organizarse y poner en práctica una estrategia. Estas habilidades también dependen del nivel de control que el individuo posea sobre su nivel de arousal ${ }^{5}$, o estado de alerta mental, en función de responder a las demandas de la situación.

Hay otros factores, que en especial, el medio educativo no puede dejar de lado, al tratar de comprender el comportamiento de las personas con trastornos de la atención y que estudios realizados por Reader y Harris (1990), Robins (1992), Dykman y Ackerman (1993), reseñados en el sitio de internet de la Fundación TDAH de Argentina (2002, p. 1), se resumen de la siguiente manera:

... estos requerimientos se entrecruzan a través de la habilidad del individuo para organizar su tiempo y su ambiente físico circundante para regular su comportamiento y funcionamiento cognitivo, para ensayar o practicar soluciones a los problemas y para practicar flexibilidad en la consideración de respuestas alternativas a los desafíos que las situaciones le van poniendo enfrente...

Las funciones ejecutivas, como se mencionó, son complejas, el trabajo de cada una de las operaciones que realizan, dependerá de múltiples factores, tales como la naturaleza de la tarea cognitiva, el entrenamiento y los hábitos académicos o cotidianos que tenga la persona, la ocupación y las habilidades y destrezas automatizadas que posea. Igualmente tienen un papel preponderante las demandas de otras tareas que se deben ejecutar de forma simultánea o secuencialmente y la orientación o guía cognitiva prioritaria que tenga determinada tarea. Por tanto, como lo plantea Pineda (1999), las funciones ejecutivas son una serie de factores organizadores y ordenadores subyacentes a todas las demás actividades cognoscitivas.

Cabe mencionar que las funciones ejecutivas son actividades propias de los lóbulos frontales. Autores como Allegri y Harris (1999) y Pineda (1999) explican que los lóbulos

\footnotetext{
${ }^{5}$ Estado de activación del Sistema Nervioso Autónomo.
} 
frontales representan un sistema neurológico muy complejo. Esta complejidad es evidente en diversos sistemas de conexiones recíprocas, entre las más importantes de señalar, para los efectos del presente trabajo, están aquellas que tienen una relación directa con las necesidades cognoscitivas de los estudiantes en el proceso de aprendizaje. Ellas son el sistema motivacional (sistema límbico), el sistema de atención sostenida (sistema reticular activador), el sistema organizativo de los reconocimientos (áreas de asociación posterior) y el sistema de control sobre las respuestas comportamentales (zonas de asociación y estructuras subcorticales). La comprensión de muchos de los síntomas manifiestos de las personas con trastornos de la atención, se explica al analizar la funcionalidad de esta estructura cerebral.

Retomando a Allegri y Harris (1999, pp. 1-2), mencionan que una lesión de la corteza prefrontal provoca dificultades en el nivel cognitivo; dificultades que afectan a las personas con trastornos de la atención y, al analizar su alcance, no queda duda de las alteraciones en el funcionamiento pedagógico que presentan los niños y las niñas con este trastorno,

... la lesión de la corteza prefrontal determina los siguientes déficit cognoscitivos: dificultades en el planeamiento, razonamiento, resolución de problemas, formación de conceptos y ordenamiento temporal de los estímulos; trastornos de la atención, aprendizaje asociativo, del proceso de búsqueda en memoria y del mantenimiento de la información en la memoria de trabajo; alteración de algunas formas de habilidad motora, generación de imágenes, manipulación de las propiedades espaciales de un estímulo, metacognición y cognición social...

La actuación de una persona profesional en educación y, por supuesto, de todos aquellos que tienen contacto con estas personas, sobre todo, en el periodo de la niñez, es fundamental, pues como se mencionó en esta etapa del desarrollo, se produce la maduración de las funciones ejecutivas; particular atención es la edad promedio, comprendida entre los 6 y los 8 años, en la cual la mayoría de los niños adquiere la capacidad de autorregular sus comportamientos y conductas, lo que les permite fijarse metas y prever y adelantarse a las situaciones, sin depender necesariamente de las disposiciones, advertencias, órdenes o sugerencias externas. Es necesario recordar que aún los niños pueden presentar conductas y comportamientos impulsivos propios de etapas de desarrollo anteriores, pero cada vez se puede apreciar con mayor claridad, la asunción que hacen de su comportamiento, de acuerdo con los parámetros sociales y personales que el medio le demanda. 
Además, la capacidad cognoscitiva de la autorregulación está íntimamente ligada al desarrollo de la función reguladora, conocida como el lenguaje interno; a la aparición de las bases del pensamiento lógico formal y a la maduración propia de las zonas prefrontales del cerebro.

Según propone la organización CHADD (Children and Adults with Attention-deficithyperactivity Disorder) (2003)

Recientemente los déficit en las funciones ejecutivas han emergido como factores centrales que impactan el éxito académico y vocacional. Expresado de manera sencilla, el término funciones ejecutivas se refiere a una variedad de funciones dentro del cerebro que activan organizan, integran y manejan otras funciones.

Algunas preocupaciones importantes se relacionan con el déficit en la memoria de trabajo y en la habilidad de planificar para el futuro.

Para efectos del objetivo de este artículo, se considera oportuno hacer a continuación, la referencia a las principales funciones ejecutivas, no sin antes señalar lo que menciona la organización ADDvisor (2001), en el sentido de que es necesario recordar que, la última meta de la intervención con las funciones ejecutivas que se presentan, a partir de los desórdenes del cortex prefrontal, es el establecimiento regular de los controles rutinarios del comportamiento. Es necesario maximizar la independencia y orientar la meta a la resolución de problemas, "... esto no es una tarea fácil y está sobre el curso de los meses y los años, no de los días y semanas". Sin embargo, lo anterior es crítico para el funcionamiento óptimo del niño en un largo plazo. Es una tarea compleja, diaria, persistente, constante y congruente, que, muchas veces no se logra al desanimarse los adultos que acompañan en la situación pedagógica y familiar, a estos niños, sin que el resultado se vea en el corto plazo. Es necesario siempre mantener en mente que el trabajo que se hace con esta población, tiene y debe tener siempre la meta puesta en el largo plazo.

Bauermeister (2001, p. 12), señala que alrededor de los 9 años, los niños logran internalizar las guías externas y la ayuda del adulto no es tan necesaria. Menciona que hay cuatro funciones ejecutivas básicas que pueden estar alteradas en el caso de los niños con trastornos de la atención. Algunas otras tienen un papel importante pero no preponderante, según la literatura, por lo que para este trabajo que busca ofrecerles a los profesionales en educación, los conocimientos básicos para que puedan atender a estos estudiantes, desde la cotidianeidad del aula se enfocará en la propuesta teórica de las siguientes funciones 
ejecutivas: La memoria de trabajo, el desarrollo del lenguaje interno, la habilidad para autorregular las emociones y la motivación y la habilidad para la solución de problemas.

- Memoria de trabajo:

Antes de iniciar la discusión relacionada con esta función ejecutiva, es necesario definir el término de memoria y la acepción que del mismo se va a tener en este artículo. Colom $\mathrm{R}$ y Flores-Mendoza C. (2001) señalan que la memoria es un atributo humano que permite a las personas desarrollar la capacidad de almacenar información para utilizarla posteriormente.

Actualmente la literatura, producto de procesos de investigación, presenta una dinámica discusión teórica entre los conceptos de memoria de corto plazo y memoria de trabajo. Algunos autores, con los que concordamos, señalan que el término memoria de trabajo es mucho más dinámico y activo que el tradicional de memoria a corto plazo. La definición de la memoria de trabajo, según la propone Bauermeister (2001, p. 13), "es la habilidad para retener en la mente aquella información necesaria para guiar las acciones de la persona al momento o más adelante".

Otros autores, que se reseñan a continuación, agregan aspectos que clarifican la importancia que tiene esta función ejecutiva, particularmente si se sitúa en el ámbito educativo.

Para Santrock (2001, p. 307), el sistema de memoria de trabajo es “... de capacidad limitada, en donde la información es retenida por un período de 30 segundos, a menos que la información sea ensayada o procesada, en cuyo caso se retendrá por más tiempo." En la misma línea, Woolfolk (1999:254) coincide en que la memoria de trabajo es la

... información en que uno se concentra en un momento dado, es el 'banco de labores' del sistema de memoria, el componente en el que la nueva información permanece temporalmente y se combina con los conocimientos de la memoria a largo plazo. Esta memoria es como un espacio de trabajo o la pantalla de una computadora, su contenido es la información activada en la que uno piensa en el momento, por lo que algunos psicólogos la consideran sinónimo de conciencia.

Esta porción de la memoria de trabajo debe estar disponible para la realización de operaciones mentales, cuando se piensa o bien cuando se debe solucionar un problema. Good y Brophy (1996) indican que no se puede afrontar tareas cognitivas complejas, sin que éstas se puedan simplificar, reduciendo la carga en la memoria de trabajo y reseñan que hay dos formas fundamentales para hacerlo: mediante la fragmentación o división de la tarea en 
subpartes tomando oportunamente una cada vez. Otra es practicar ciertas habilidades, hasta que se vuelvan automáticas, de manera que puedan ser usadas con poco o ningún esfuerzo consciente, lo que permite dejar la memoria de trabajo libre para asumir otras tareas.

Un ejemplo de esto último que facilita su comprensión y que los autores antes citados lo señalan, es el proceso de conducir un carro. De alguna manera, la práctica de las habilidades necesarias para conducir, se repiten hasta alcanzar un grado mayor o menor de eficiencia con el cual se maneja. Las habilidades se han vuelto automáticas y eso permite que el individuo pueda dedicar su memoria de trabajo a atender otras tareas; por ejemplo, conversar o cantar, mientras se realiza la acción de manejar. Conducir es una tarea compleja que tiene, entre otras cosas, un orden dado, dependiendo de lo que se quiera lograr. El orden y los movimientos corporales se automatizan y, por eso podemos hacer otras acciones mientras conducimos.

Good y Brophy (1996) plantean que lo mismo que se hace cuando se conduce, es lo que aplican los estudiantes exitosos para enfrentar las tareas académicas que les demanda el medio. En el caso de las personas con trastornos de atención, muchas de las habilidades que requieren para tratar la información en la memoria de trabajo, parecen funcionar intermitentemente, a veces pueden desagregar una tarea y atender sus partes y lograr mantener la atención enfocada o focalizada durante un tiempo; dirigirla y organizarla e invertir esfuerzo en sostenerla para no distraerse y llegar a cumplir con la meta propuesta o solicitada. Otras veces la internalización de los procedimientos o las habilidades para la ejecución de la tarea, no son homogéneas o no persisten el tiempo suficiente, como para lograr llegar a la meta. No se trata de que carece de los recursos para que la memoria de trabajo funcione adecuadamente, sino que la alteración en las estructuras cerebrales, no le permite funcionar con la precisión que lo hacen sus contemporáneos.

Baddeley (citado por Santrock, 2001, p. 308) ha trabajo en la década de los 90's en la propuesta de un modelo de la memoria de trabajo. Considera que esta memoria permite a los individuos:

... manipular, reunir y construir información cuando toman decisiones, solucionan problemas y comprenden el lenguaje escrito y hablado. En el modelo de Baddeley, la memoria de trabajo consiste en un 'ejecutivo' general y dos subsistemas, que ayudan al ejecutivo a realizar su trabajo... uno de estos subsistemas es el circuito de expresión verbal, que se especializa en procesar la información del lenguaje. El otro subsistema es el procesamiento de información visoespacial, que incluye habilidades imaginativas, como visualizar un objeto o una escena. 
Por su parte, Puente Ferrara (2001, p. 19), al referirse a los trabajos de Baddeley y la organización de la memoria de trabajo que este propone, indica que para comprender lo que diariamente hacemos en esta memoria, es importante concebirla como "la alianza de dos componentes auxiliares (el bucle articulatorio y la agenda visoespacial) capitaneados por el ejecutivo central". Este último es el responsable del control de todo el sistema cognitivo, pues determina cómo deben tratarse las entradas de información y la recuperación de la misma de la memoria de largo plazo. Se concibe como multimodal, pues es capaz de combinar información que procede de diversos canales sensoriales, así como de diversas fuentes de estímulos. Al referirse al bucle articulatorio, el mismo autor indica que este tiene dos componentes: un almacén fonológico en el cual guardamos o procesamos información, basada en el lenguaje y un proceso de control articulatorio, basado en el 'habla interna', al cual haremos referencia posteriormente. Además el componente denominado visoespacial, está exclusivamente dedicado a la representación de toda aquella información que proviene de las imágenes visuales.

Oberauer y otros (2000) citados por Colom y Flores-Mendoza (2001), señalan las funciones de la memoria de trabajo y han distinguido tres tipos:

a) Las de almacenamiento y procesamiento que exigen mantener activos en un estado accesible, los contenidos mentales y, por otro, transformar los contenidos a través de las operaciones mentales.

b) Las de supervisión que suponen tutelar y controlar las operaciones y acciones mentales.

c) Las de coordinación que suponen, a su vez, tres cosas:

- Coordinar la información de diferentes fuentes

- Coordinar operaciones mentales sucesivas en una secuencia

- Coordinar los elementos en estructuras.

Asimismo, los autores antes mencionados, se refieren a sus descubrimientos y los de colegas que señalan los ámbitos de los dominios de contenido de la tarea que se da en la memoria de trabajo y que tienen relación con lo verbal, lo numérico y lo figurativo. No obstante, ellos mismos señalan la necesidad de mayor investigación al respecto, porque aún se tienen vacíos conceptuales y de conocimiento para una real comprensión de esta función tan compleja. 
Como puede apreciarse, el papel de la memoria de trabajo, es central en el comportamiento y en el logro de las metas de las personas. En el caso de un niño o de una niña que está en la escuela, esta función ejecutiva le permite guiar las acciones en el momento que se requieren o más adelante, si es del caso. Por ejemplo, llevar el libro y el cuaderno de matemáticas de la escuela a la casa; leer las páginas que le ha asignado el profesor; resolver los ejercicios de práctica y entregar esa tarea en la clase siguiente. Esta función es indispensable para recordar hacer las cosas en el futuro cercano, tal y como señalan Bauermeister (2001), Santrock (2001), Colom y Flores-Mendoza (2001), Mendoza (1999), y Allegri y Harris (1999).

En el caso de las personas con déficit de atención, la dificultad para inhibir impulsos entorpece la función ejecutiva de la memoria de trabajo. El resultado de esto es que los niños, niñas, adolescentes o personas adultas se manifiestan como distraídos; olvidadizos para hacer las cosas o llevar algún material cumplir una orden; seguir una instrucción o, bien, se muestran desorganizados. Esta misma inhibición de los impulsos, los hace propensos a no terminar las tareas; a no pensar en las consecuencias de lo que hacen o piensan; a no aprovechar las experiencias pasadas y capitalizar esa experiencia en el futuro. También esta es la explicación para la problemática en el manejo del tiempo que tienen estas personas.

Woolfolk (1999, p. 254) señala que "muchos profesores parecen olvidar en sus clases que la capacidad de la memoria de trabajo es limitada. Muchas veces incluso la información se mantiene solamente por algunos segundos y, además, la literatura (Puentes Ferrera, 2001; Colom y Flores, 2001, Mendoza, 1999, entre otros) indica que se pueden manejar entre 5 y 9 elementos a la vez. Al recordar que la memoria de trabajo se relaciona con la información 'nueva' que la persona debe manejar y, que paralelamente el cerebro debe realizar el proceso de búsqueda de los conocimientos y experiencias que se tienen en la memoria de largo plazo para comprender la situación o los datos que se están dando. Es claro, entonces, que para llevar a cabo exitosamente esto, se requiere una cierta capacidad de atención y de concentración que permita atender y entender lo que está sucediendo. Necesario es también aclarar en este punto que cualquier distractor, por pequeño que sea, va a entorpecer o inhibir el orden que tiene la memoria de trabajo y va a dar, por consiguiente, al traste con el procedimiento. En el caso de las personas con trastornos de la atención, esto es especialmente válido y explica por qué, a pesar de que el alumno parece escuchar y tiene entrenamiento suficiente para cumplir con las demandas del medio, los resultados no siempre son satisfactorios. 
Para que la información de la memoria de trabajo se mantenga activa y pierda la fragilidad que la caracteriza, se requiere que exista la retención. La actividad es intensa en la memoria de trabajo, mientras la persona esté concentrada, pero decae si la atención se enfoca sobre otra u otras situaciones o si se presenta algo que llame más la atención. Para que no se presente el olvido, el cerebro puede hacer dos procedimientos: el repaso mental entendiéndose éste como "un proceso de control ejecutivo que influye en el flujo de la información por el sistema que se encarga de su procesamiento" según lo define Woolfolk (1999, p. 255). Este repaso puede darse a partir de:

- el repaso mental de mantenimiento que es aquel en el cual la información se repite en el denominado circuito articulatorio que la puede mantener por alrededor de 15 segundos.

- El repaso elaborativo que es aquel, en donde en el nivel cerebral, se trata de conectar la información con otra existente o que ya se conoce y que está almacenada en la memoria de largo plazo.

El segundo mecanismo es el proceso de control por agrupamiento, mediante el cual se puede retener información si esta se reúne en grupos de datos, los cuales son más fáciles de recordar.

Estos procesos son necesarios para que la persona pueda permanecer ubicada en el medio y en la situación en que está y pueda seguir funcionando de manera acertada. Lo cual le permitirá cumplir con las instrucciones y la tarea que se le está solicitando o que debe recordar para desarrollarla después.

Cuando se da la interferencia de nuevos pensamientos que, dicho sea de paso, en el caso de los niños, niñas y adolescentes con trastornos de atención, es lo que comúnmente sucede, -es casi, podríamos afirmar, la norma de su contacto con el mundo que le rodea-, el 'viejo' pensamiento es desplazado o reemplazado por el nuevo, lo que facilita el olvido de todo o partes de la información que tenía guardada en la memoria de trabajo. Lo mismo sucede con la pérdida de interés en lo que estaba guardando en la memoria de trabajo. Por lo que la activación de esa información decae o se debilita y llega a desaparecer. Estos dos procesos, el de interferencia y el de decaimiento, explican muchas de las características que tanto llaman la atención en estos niños y que se suelen calificar de despistados, olvidadizos, distraídos o, en el peor de los casos, de desorganizados, al tener solamente parte de la información para guardar en la memoria de largo plazo o para procesar en la memoria de trabajo. Lo más grave aún es que el niño no tiene conciencia de lo que le sucede y pretende 
asumir la tarea con la poca información que logró procesar, lo que le lleva necesariamente al fracaso.

Por su parte, Puente Ferrera (2001, p. 19) al señalar que la memoria de corto plazo o memoria de trabajo "es el lugar del control del sistema de memoria: ella determina qué información será atendida, cómo va a ser procesada y qué mecanismos intervendrán para la recuperación", lleva a concluir para los fines del presente artículo, que todos estos procesos son medulares, al referirnos a los procesos de aprendizaje y a los requisitos que un alumno debe tener dentro del aula para poder funcionar de manera adecuada, cumplir con las múltiples instrucciones y procesar los datos para que se produzca el aprendizaje.

Finalmente para recapitular, en este apartado, se hace eco a lo manifestado por Tannock y Martinussem (2001) en el sentido de que la memoria de trabajo juega un papel importante en ayudar a la mente a concentrarse y 'colar' las distracciones. Es necesaria para el desarrollo de las actividades cognitivas complejas, incluyendo las actividades académicas de la lectura, la matemática, la planeación y la resolución de los problemas. Al estar alterada esta función ejecutiva, puede ser la responsable de algunos de los síntomas conductuales de la persona con trastorno de la atención, igual que de algunas de las deficiencias en el rendimiento académico que ellas presentan.

\section{- Desarrollo del lenguaje interno}

Fernández Tubair (s.f., consulta en Internet) establece que la función ejecutiva del lenguaje interno, es darle orden y significado a las cosas; permite un cierto sistema de "invención" de palabras y significados que le permiten aprender y comunicarse y puede ser modificado al conocer las palabras correctas. Por su parte, Good y Brophy (1996, p. 68) señalan que "el discurso interno es pensamiento verbalizado, el hablarse a sí mismo que ocurre cuando se piensa". Esto, según los autores, es un proceso. Los niños al acercarse al pensamiento operacional, van desplazando su discurso interno hacia la tarea que se debe cumplir y, en forma creciente, parecen estar hablando consigo mismos. En edades de la infancia y la niñez temprana, es común escuchar a los niños verbalizar sobre lo que están haciendo o pensando. En ocasiones, es posible seguir la resolución de un problema que están enfrentando con solo escuchar lo que están diciendo. Más tarde, su discurso se vuelve más ininteligible, debido a que el niño ha desarrollado las habilidades para manejar la mayor parte del pensamiento en forma silenciosa.

Berk (1986), citado por Good y Brophy (1996), reportó un interesante estudio sobre el discurso interno que pronuncian los niños y que arroja, para efectos del presente escrito, 
información importante para la comprensión del proceso ejecutivo que significa el lenguaje interno. Este autor trabajó con estudiantes de primer y tercer grados durante el tiempo que desarrollaban un trabajo de matemática en su pupitre. En el análisis longitudinal que realizó, encontró que el discurso privado era cada vez más relevante para la tarea y menos audible. Los estudiantes con alto rendimiento entraron en el ciclo del discurso privado más rápidamente que los estudiantes con bajo rendimiento académico. Los niños de primer grado del alto rendimiento, utilizaron formas más maduras con respecto a sus otros compañeros. Aunque su discurso privado era más audible, este tenía como objetivo, ayudarse en el pensamiento para enfrentar el reto de la resolución del problema y este con el tiempo, derivó en una internalización del discurso de manera más rápida, en comparación con el momento en que sus pares lo lograron. En esta misma línea, otro estudio de Berk reseñado por Craig (2001), plantea que los niños entre los cuatro y los ocho años, hablan en voz alta cerca del $20 \%$ del tiempo, cuando las escuelas lo permiten.

El pensamiento es una función auxiliar temporal del aprendizaje, al igual que se utiliza transitoriamente, contar con los dedos para enfrentar la aritmética y pasar a formas de funcionamiento más complejas. Cuando ya el niño no necesita la verbalización en voz alta, comienza a murmurar y, por último, a pensar en silencio. Este ciclo en realidad no termina; algunas personas aún siendo ya adultas, recurren al proceso de verbalizar en voz alta y murmurar de manera ocasional, cuando tratan de resolver un problema, particularmente si este es complejo.

En la etapa de desarrollo cognitivo operacional, los esquemas tanto verbales como cognitivos, se asimilan y se coordinan en potentes y diferenciados esquemas que se van convirtiendo en estrategias para utilizar procesos, como aprender a aprender; la lógica operacional concreta y otras habilidades de procesamiento de la información y de la resolución de problemas.

Vygotsky (1962), citado por Santrock (2001), propuso que un niño pequeño usa el lenguaje no solo para comunicarse con los demás, sino también para planear, guiar y monitorear su comportamiento en un proceso de autorregulación. El uso del lenguaje para la autorregulación se llama comunicación interna o comunicación privada. Para Piaget, la comunicación privada es egocéntrica e inmadura, pero para Vygotsky es una herramienta importante del pensamiento, durante los primeros años de la niñez. Compartimos el criterio propuesto por Vygotsky, pues a la luz de las funciones ejecutivas y de la comprensión de los trastornos de atención, la dificultad que enfrentan los niños con esta condición, se mejora 
notablemente, cuando se le facilitan procesos de desarrollo de su habla o su discurso interno.

Los niños, según Vygotsky, primero utilizan la comunicación social por su necesidad de interactuar con las otras personas y, esto lo hacen, antes de enfocarse en sus propios pensamientos. La transición entre la comunicación externa o social a la interna o privada se presenta entre los tres y los siete años y tiene como función primordial, el hablar consigo mismo. Después de un tiempo de usar el lenguaje interno en el nivel oral, convierte el hablar consigo mismo en una incorporación natural y se hace capaz de actuar, sin verbalizar por lo que ha interiorizado su habla egocéntrica en la forma de un discurso interno que se convierte en parte de sus pensamientos. Vygotsky (1962) plantea que los niños que usan mucho la comunicación privada son más competentes socialmente que quienes no lo hacen; "cuando un niño habla para sí mismo está usando un lenguaje que gobierna su comportamiento y que lo guía", según se lee en Santrock (2001, p. 69).

De lo anterior se deduce que lo esperable, es que a partir de los siete años, el lenguaje interno de los niños esté incorporado, asumiendo el papel de autorregulador del comportamiento. Los niños con trastornos de atención, no tienen adecuadamente desarrollado el lenguaje interno. Para cualquier tarea que necesiten cumplir, requieren que se le enseñe a valorar todas las alternativas de la misma, que pueda analizar, concentrarse y pueda comprobar parcial y globalmente, los resultados una vez finalizada. No es el pensamiento interno el que lo hace, sino más bien, es la acción la que conduce el pensamiento y, para esto, requiere la verbalización.

En el sitio www.genaltruista.com (2000) se plantea que el lenguaje interno, lo utilizan todas las personas. Es información que circula por las neuronas en forma de ondas eléctricas y está estructurado de una manera personal. Permite la estructura y la reestructuración de los significados en forma armónica y equilibrada con la organización inicial que se tiene.

Retomando la propuesta de Vygotsky, (citado por Craig 2001, p. 224), en la búsqueda de comprender la importancia de esta función ejecutiva y, cómo su desarrollo tardío y muchas veces inconsistente en las personas con trastornos de la atención, provoca dificultades para el buen desarrollo académico, éste plantea que el habla privada o interna refleja el habla social de los adultos y contribuye a desarrollar el pensamiento interno y la autodirección.

Hay tres etapas o momentos en el desarrollo del habla privada:

a) Cuando ocurre después de una acción 
b) Cuando acompaña las acciones

c) Cuando precede a la acción

Las personas con trastornos de la atención, presentan sus mayores dificultades en la etapa c), que es justamente cuanto las personas logran el proceso de planeamiento del curso de una acción. Cuanto más un niño logre la capacidad de planear sus acciones, más se puede apropiar de ellas; mejor las puede organizar y dirigirlas a la consecución de las metas. La regulación que se logra, cuando se internaliza el lenguaje, permite el manejo de los pensamientos de manera ordenada y disponer de un panorama, cada vez más completo, de lo que se debe hacer.

En el caso de las personas con trastornos de atención, este panorama no se logra completar, pues la dificultad para que el pensamiento preceda la acción, les lleva, por ejemplo en el plano académico, a no terminar las tareas encomendadas; no contar con todos los materiales para hacer el trabajo, aunque conozca que los necesita; a no esperar turno para hablar; a decir cosas en un momento que es inoportuno, etc. Así el lenguaje interno, permite a los niños la autorregulación de su propia acción al hacer posible pautas de comportamiento que le facultan la resolución de las dificultades; es decir, la planificación de la acción mediante la regulación interna.

Bauermeister (2003) indica que el lenguaje interno, esa voz privada de la mente que se usa para conversar con uno mismo, dirige el comportamiento y es de especial importancia, cuando se sitúa al niño en el centro educativo. Ese hablar consigo mismo, pone el autor de ejemplo, es lo que permite al estudiante decirse a sí mismo expresiones como: "debo fijarme en el signo del ejercicio para ver si es una suma o una resta", o bien "debo tildar una palabra, porque es esdrújula y todas las esdrújulas se tildan". Sin embargo, cuando la inhibición de impulsos interfiere con esta función ejecutiva, el resultado es una falta de autorregulación de la conducta, afectándose habilidades como la capacidad para seguir instrucciones de manera cuidadosa y completa y la habilidad para dar seguimiento a los planes y a las tareas por hacer en el hogar o la escuela. Estos aspectos son esenciales para el cumplimiento de las demandas que el medio escolar hace al niño. Además del desconcierto que provoca en la persona profesional en educación la variabilidad de las respuestas que da el niño y la baja calidad del trabajo académico que se produce por estos "descuidos".

Armstrong (2001, p. 77), citando a Dyson (1987) señala que "la conducta verbal extraescolar de los niños los ayudaba a desarrollar destrezas intelectuales", En su libro "Síndrome de Déficit de Atención con o sin Hiperactividad. Estrategias en el Aula", señala que observó que los niños organizan gran parte de su pensamiento, a través del discurso 
privado, o sea el proceso de hablarse a sí mismos o a nadie en particular, a medida que crecen, las palabras se van internalizando en forma de un discurso interior. La charla paralela de los niños y las niñas cuando juegan, es reemplazada por la "conversación mental silenciosa" de los adultos cuando trabajan. La mayoría de los niños al llegar a la escuela, ya ha desarrollado parte de la habilidad para el "autodiscurso", caracterizado tanto por la privacidad, como por el silencio. Sin embargo, la mayoría de los niños con déficit de atención no ha logrado el desarrollo de esta habilidad, ni parcial ni totalmente. Por lo que sería muy valioso, recomienda, que los docentes organicen su aula y el trabajo escolar de manera que esos niños empleen su discurso privado natural en horas de clase, y no como sucede actualmente que la conducta verbal se usa para reafirmar el diagnóstico del déficit de atención. Es conveniente que los docentes comprendan que estos alumnos podrían necesitar de su capacidad natural de hablarse a sí mismos mientras trabajan para poder desarrollar mejor su pensamiento, y para ver esta conducta como una ventaja académica con la que se puede apoyar a los alumnos y, más bien, enfocar su esfuerzo en la creación de estrategias que le permitan a los niños repasar en voz muy baja, lo que debe hacer, paso a paso, y con esto lograr que controle la distracción y la impulsividad característica del trastorno.

Reforzando lo anterior, García Castaño (2001, p. 38) señala que mediante el lenguaje interno se establecen las reglas y preceptos que guían la conducta, "cumple la función de regular el comportamiento, por medio de él solucionamos problemas, nos fijamos metas y establecemos los procedimientos y estrategias necesarias para alcanzarlas". En caso de no desarrollarse eficientemente esta función ejecutiva, entonces el individuo podría ir por la vida sin ejercer autocontrol eficaz que es lo que, en muchas ocasiones, se percibe en las persona con déficit de atención: actúan con una desorientación constante y ellos son los primeros sorprendidos de las cosas que les suceden.

\section{- Habilidad para autorregular las emociones y la motivación}

Good y Brophy (1996) señalan siguiendo a Bandura (1986), que la autorregulación es la capacidad cognoscitiva a través de la cual, mediamos el aprendizaje. El modelamiento y los procesos de socialización son significativos para el desarrollo de las normas concernientes a la conducta que es aceptable o inaceptable. Algunas de las normas responden a ideales universales y, otras, son de carácter personal. Generalmente están relacionadas con los valores y aspiraciones que tenga el individuo. 
El manejo personal positivo hace que las personas se sientan capaces, y los niños no son ajenos a esto. Cuando la persona se sabe capaz, tiene mayores posibilidades de controlar la impulsividad y de cambiar sus atribuciones para el fracaso en pro del éxito. Los niños con trastornos de atención, necesitan que en el aula (y en el hogar también), se les enseñen estrategias cognoscitivas y que sean razonables las expectativas que se tengan sobre su desempeño. La conciencia que tienen los estudiantes, en general, sobre sus capacidades cognoscitivas puede permitirles controlar su propio aprendizaje, lo cual bajo ciertas condiciones, puede ser un factor de motivación o no. Puede motivarlos a buscar tareas más desafiantes y a persistir frente a las dificultades o, por el contrario, puede llevarlos a la desmotivación, al desánimo, a buscar alternativas de "ser alguien" en el centro educativo, recurriendo a conductas perturbadoras y oposicionistas

El papel que puede tener el y la docente para facilitar la autorregulación de los estudiantes es alentarlos, poco a poco, para que desarrollen su capacidad de autorregulación. Si todos los estudiantes requieren esta ayuda y soporte de parte de sus maestros, con mayor razón lo requieren los niños con trastornos de la atención.

En líneas anteriores se ha hecho referencia a las consecuencias socioemocionales que viven las personas con trastornos de atención, por lo que aquí destacaremos el papel que pueden tener las personas adultas y, especialmente, los docentes en el desarrollo de la autorregulación. En primer lugar es muy importante tener claro que la autorregulación varía dependiendo de la edad y la historia de vida a que ha estado expuesta la persona, así como de las expectativas y las intenciones que se tienen de ella. De acuerdo con lo anterior, la forma en que el docente define su propio papel, va a ser muy importante para el trabajo con los alumnos.

Las personas deben regular su comportamiento y, para el caso que nos compete, los niños deben poder regular también su proceso académico dentro de aula y además hacerlo lo mejor posible. Por lo tanto, la socialización es el proceso por excelencia, mediante el cual, se va desarrollando la autorregulación. Los más pequeños necesitarán más atención y guía que los mayores, pero siempre con la perspectiva de desarrollar los procesos de autonomía y de adaptación al medio.

El medio escolar plantea retos a los estudiantes, en cuanto a los procesos de autorregulación. Por ejemplo, se debe aprender cómo establecer objetivos y demorar la gratificación, saber cómo buscar los recursos materiales y humanos necesarios para cumplir con las tareas. Se debe saber cuándo es oportuno interrumpir una clase y cuándo es mejor esperar. Se debe conocer y respetar las rutinas establecidas para la organización del aula y 
del trabajo escolar. Se debe respetar las normas de convivencia interpersonal. Caso contrario el choque en las relaciones interpersonales; el fracaso en el cumplimiento de las actividades escolares y la irregularidad en la cotidianidad del espacio escolar, incitan reacciones emocionales que terminan lastimando la autoestima y un rechazo a la actividad escolar provocado por la falta de motivación.

Entre los aspectos que reporta la literatura que un docente debe tener presente cuando va a facilitar procesos de autorregulación con este grupo poblacional, hay dos que requieren especial mención. Por un lado el manejo del tiempo y, por otro, los procesos de autoevaluación. Con respecto a lo primero, es importante que se desarrolle el autocontrol para estimar la cantidad de tiempo que se requiere para organizar, ejecutar y terminar una determinada tarea, decidir cuándo y dónde se puede hacer la tarea. La puede realizar en el momento, en la casa o esperar hasta el día siguiente; conocer si tiene todos los materiales y la información necesaria que requiere para hacer el trabajo y establecer las estimaciones de cuánto tiempo tiene que invertir para lograr el objetivo. Esto último va de la mano con el segundo aspecto relacionado con la autoevaluación. La persona debe conocer y reconocer en sí misma, sus capacidades personales para la comprensión de instrucciones, para reconocer sus potencialidades y sus debilidades, antes de iniciar el trabajo. Solamente si estos aspectos se desarrollan con disciplina y constancia, se está en capacidad de autorregular el comportamiento y cumplir, a cabalidad, con lo que el medio requiere.

Por lo anterior es necesario agregar que la autorregulación demanda de la persona, el reconocimiento de un proceso adaptativo que significa saber cuándo los objetivos o metas se deben mantener y cuándo se hace necesario cambiarlos.

Santrock (2001, p. 291), reafirma la importancia de un buen modelo para el desarrollo de las habilidades de autorregulación, señala que “... los modelos pueden enfocarse... (en la) planeación y manejo efectivo del tiempo, atención y concentración, organizar y codificar la información en forma estratégica, establecer un ambiente productivo de trabajo y uso de recursos sociales". Continúa mencionando que los niños "al observar esos modelos pueden llegar a creer que ellos también pueden ser capaces de planear y manejar adecuadamente el tiempo, lo cual crea un sentimiento de autoeficiencia para la autorregulación académica y motiva a los estudiantes a dedicarse a estas actividades".

Según Bandura (1997), Schunk y Zimmerman (1997) citados por Santrock (2001), la autoeficiencia puede influir en las elecciones que hacen los estudiantes, el esfuerzo dedicado, su estabilidad y rendimiento. 
Para las personas con trastornos de atención, el desarrollo de la función ejecutiva de la autorregulación es fundamental para su éxito personal y académico, pues ellos requieren sentirse y ser exitosos. Ya se han señalado las dificultades que tienen los niños para cumplir, sostener, mantener y completar una tarea, lo cual lastima mucho su autoestima y, por supuesto, se refleja en los reportes de calificaciones. Si se logra que los estudiantes se sientan seguros y capaces, con un nivel adecuado de autoeficiencia para adquirir una habilidad o para ejecutar una tarea, tienen una mayor disposición hacia el trabajo; mayores recursos para mantener la motivación al logro, trabajan más fuerte y con mayor persistencia y presentan mejores rendimientos.

La meta en el desarrollo de la autorregulación, es lograr que "los estudiantes sean responsables de su propio comportamiento, de llegar a obtener un grado educativo y de convertirse en ciudadanos que contribuyan con su sociedad", según lo señala Santrock (2001, p. 201). Esta misma meta es la que debe plantearse con el niño que presenta déficit de atención. Podrá ser que se requiera más tiempo, más dedicación y más consistencia, pero ellos tienen el derecho y los recursos para desarrollar los procesos de autorregulación necesarios para el éxito en su vida.

Cabe mencionar, como lo señala Peña, (2001, p. 13) que la conducta impredecible, vista sobre todo por el maestro en el sentido de que a veces ésta "es adecuada y a veces no lo es, en algunas ocasiones el niño puede responder positivamente ante el aprendizaje y en otras ocasiones no. Esta situación puede crear falta de credibilidad en la existencia real del trastorno". La falta de autocontrol que caracteriza a los niños con trastornos de la atención con o sin hiperactividad, no se debe a que existe alguna lesión y menos que esta sea permanente, como para esperar que siempre se presente. Por el contrario, lo que lo caracteriza es la inconsistencia del síntoma, en este caso la falta de control. No obstante, como señala Bauermeister (2001, b), es necesario ayudarle a descubrir, desarrollar, demostrar y disfrutar sus habilidades:

El hecho de que su hijo o estudiante tenga dificultades para autorregular el comportamiento no descarta que tenga numerosas habilidades. El es un niño como cualquier otro. Es necesario buscar y resaltar sus fortalezas... Estas habilidades tienen el potencial de ser fuente de orgullo y logros. Más importante aún, las mismas pueden llegar a ser más prominentes en la vida del niño que sus propias dificultades. 
Para un profesional en educación, conocer que las dificultades de autorregulación son parte de un trastorno y no propias de la voluntad del niño, permite replantear su trabajo, desde la perspectiva del apoyo al desarrollo integral y facilitar los procesos con dosis de compromiso y responsabilidad que son fundamentales para alcanzar el éxito escolar.

\section{- Habilidad para la solución de problemas.}

La habilidad para resolver problemas permite la superación de los obstáculos que se presentan de manera que se siga manteniendo la motivación al logro y la sensación de ser capaz de tener éxito. En los niños con déficit de atención, la dificultad manifiesta de inhibir algunos impulsos, obstaculiza esta función y, por tanto, aumenta la frustración y el no llegar a buscar alternativas para vencer y superar las dificultades.

Parte importante en el proceso de apoyo a los estudiantes, es prevenir los problemas; identificar las áreas de peligro, por ejemplo, situaciones provenientes del ambiente que pueden generar conflictos y tener siempre alternativas de intervención en el nivel preventivo, de apoyo y también correctivo.

Las dificultades que presentan los niños en esta función ejecutiva, se derivan de las dificultades en el mantenimiento de la atención y en la impulsividad, prioritariamente. Ambos procesos, al estar ausentes en la mayoría de las ocasiones, provocan que el niño no pueda identificar que está ante una dificultad y que debe utilizar el conocimiento y la experiencia que tiene para poder resolverlo y seguir adelante. En muchas ocasiones, estas personas se quedan dando vueltas a las situaciones conflictivas sin poder remediarlas, porque no han podido identificarlas, al no poder enfocarse y mantener la atención el tiempo suficiente, como para analizar y reflexionar sobre ellas.

La literatura consultada en cuanto a la resolución de problemas señala, entre otras cosas, que es una función primordial de la escuela que debe tener como propósito, enseñar a los estudiantes a resolver problemas de matemática, de física, de salud, de estudios sociales, de ajuste personal, etc. La mayoría de los niños puede desarrollar las habilidades y destrezas que estas metas requieren. Woolfolk (1999, p. 294) señala que un problema tiene tres partes, a saber:

- Una condición inicial (la situación actual).

- Una meta (el resultado deseado).

- Una ruta para alcanzarla que incluye las operaciones o actividades.

Las personas que buscan solucionar un problema, deben estar en capacidad de establecer y cumplir submetas que les permitan avanzar y llegar a la solución. Como puede Volumen 6, Número 1, Año 2006, ISSN 1409-4703 39 
apreciarse son muchos los procesos cognitivos que se requieren, teniendo la mayoría de ellos como común denominador, la necesidad de enfocar y mantener la atención para cumplirlos. Por otra parte, la "solución de problemas" no siempre es de carácter mecánico; en la mayoría de los casos, lo que se demanda del estudiante es que las nuevas respuestas rebasen la simple aplicación de las reglas aprendidas y que la persona pueda utilizar estrategias nuevas en la búsqueda de soluciones alternativas que, en última instancia, van a permitir la creación de conocimiento o, situándonos en el medio escolar, van a facilitar la comprobación de la comprensión del conocimiento estudiado.

De acuerdo con lo anterior, es necesario agregar que la solución de problemas puede requerir de dos procesos diferentes. Por un lado, aquellos que demandan el uso de estrategias generales y, dependiendo de la especialidad del área que se esté trabajando, el uso de estrategias específicas que respondan al dominio esperado por la persona que está resolviendo el problema.

Las estrategias, que generalmente se utilizan para solucionar un problema, pueden ser aprendidas. Aquel que las enseña debe tener claro el conocimiento que está demandando para que sea un buen guía. Si hablamos del ámbito escolar, un requisito que debe tener el docente, es poder desagregar y recorrer, con los alumnos la estrategia o estrategias para solucionar los problemas. Esto será de gran ayuda para los niños con trastornos de atención.

El proceso de resolución de problemas ha sido reseñado con muchos autores. Entre ellos Bransford y Stein, citados por Woolfolk (1999), proponen el siguiente proceso:

- Identificar el problema y sus oportunidades.

- Definir las metas y representar el problema.

- Explorar las estrategias posibles para su solución.

- Anticipar los resultados y actuar.

- Retroceder y aprender.

En cualquiera de estos momentos, como se mencionó, el niño con déficit de atención podría presentar dificultades que lo llevarían al fracaso y a la frustración emocional que caracteriza el desempeño académico de estas personas.

La dificultad de seguir este procedimiento, que dependiendo de la edad del niño y el desarrollo cognitivo que tenga, puede resultar de fácil realización; se convierte en un reto y desafío muy grande para los niños con deficiencias atencionales y, si a esto se le agrega la impulsividad que las acompaña, estamos ante un verdadero problema. 
Como menciona Scandar y Puente (2003, p. 12), en relación con la necesidad de enseñarles a las personas con trastornos de la atención con o sin hiperactividad, estrategias para resolver problemas que les faciliten la forma de abordar las situaciones difíciles o demandas del medio escolar:

... el niño con problemas de inatención, hiperactividad e impulsividad presenta dificultades para inhibir ciertas respuestas automáticas, desarrollar pensamientos alternativos, evaluar consecuencias, etcétera. La ejercitación repetida en los temas que se esconden detrás de las siguientes preguntas producirá grandes resultados a largo plazo ¿Cuál es el problema? ¿Tiene solución? ¿Hay más de una solución posible? ¿Qué obstáculos anticipo? ¿Cómo podré afrontarlos?

La capacidad que desarrolle un docente para facilitar que los niños, en general y particularmente aquellos con déficit de atención, puedan aprender a resolver problemas, va a permitir que se controlen mejor muchas de las dificultades académicas que presentan en la vida cotidiana del aula y fuera de ella, si pensamos en el futuro.

Las funciones ejecutivas, con los procesos, habilidades y destrezas antes descritas, son fundamentales para que la persona pueda aprender y, es en ellas, donde la mayoría de los niños y adolescentes con déficit de atención con o sin hiperactividad, presenta problemas $y$, por tanto, su rendimiento académico se afecta $y$, con ello, su autoestima y las relaciones interpersonales, especialmente con su madre, su padre y con los maestros. Son estudiantes en la mayoría de los casos y, al inicio de su período escolar, demuestran mucho interés por las actividades académicas, pero no ven recompensado su esfuerzo con calificaciones acordes con el tiempo invertido en ello.

En una cultura como la costarricense, que ha centrado muchos de sus objetivos educativos en la representación social de las calificaciones, estos bajos rendimientos afectan mucho la calidad de vida de los niños y adolescentes y las de sus familias, así como las posibilidades de un desarrollo vocacional que le permita opciones profesionales o de obtener una buena calidad de vida en el futuro. Es necesario recordar que estas situaciones se vuelven más difíciles de manejar, por cuanto son estudiantes que demuestran tener un nivel intelectual adecuado y, en muchas ocasiones, arriba del promedio, por lo que muchos maestros, maestras, padres y madres, no logran entender $y$, por tanto, manejar adecuadamente la aparente contradicción que se presenta entre inteligencia y rendimiento académico. 
Se requiere tener presente, particularmente los docentes, así como los padres y madres, que las personas con déficit de atención, siguiendo lo propuesto por Rief (1998) y Scandar (2000), responden muy bien al estímulo y al refuerzo positivo. Son originales y poseen un buen sentido del humor, cuando el medio les permite su desarrollo y uso. Tienen una atracción marcada por lo novedoso y su habilidad para tomar riesgos bien encaminada, los puede hacer creativos y marcar la diferencia en la familia o el grupo académico, lo mismo que su diversidad de intereses. Además son personas intuitivas, sensibles, espontáneas, con una destacada intensidad emocional para vincularse con los otros y una alta capacidad energética que los vuelven incansables, perseverantes y tenaces. Son las personas adultas las que pueden hacer la diferencia en la vida de estas personas; bien orientados y con oportunidad de ser exitosos, alcanza la plenitud existencial a la que aspira la mayoría de las personas.

Finalmente parafraseando a Sam Goldstein (s.f., p. 2) el individuo que reúne un número de síntomas que causan una crónica y significativa disminución en su desempeño en múltiples contextos de su vida, paga su precio en una sociedad compleja como la actual. El diagnóstico sugiere que el trastorno es persistente $\mathrm{y}$, por ende, es un estado permanente. No obstante lo anterior, el autor menciona que "afortunadamente los síntomas de TDAH pueden ser tratados y con eficacia conduciendo (sic), a quienes pueden luchar con su capacidad disminuida para el autocontrol a vidas exitosas y felices".

\section{Referencias}

ADDvisor. (2001). Review executive function deficits in ADHD and organizational strategies to manage them. En An E-mail Newsletter for individuals with AD/HD and their Families. October 1, 2001. Volumen 3, número 19. (Traducción libre de Carmen Cubero para uso de esta investigación)

Allegri, Ricardo y Harris, Paula. (1999). La Corteza Prefrontal en los Mecanismos Atencionales y la Memoria. (Prefrontal Cortez in Memory and Attention) Ponencia presentada en First International Congress on Neurophysiology in Internet. http://www.uninet.edu/union99/congress/confs/syn/01Allegri.html

American Psychiatric Association. (1995). DSM-IV: Manual de Diagnóstico y Estadística de los Trastornos Mentales. [Versión en español]. Barcelona: Masson.

American Academy of Child \& Adolescent Psychiatry. http://www.aacap.org/publications/apntstam/noattent.htm

Añaños, Elena. (2001). Psicología de la atención y de la percepción. Guía de estudio y evaluación personalizada. México: Alfaomega. 
Armstrong, Thomas. (1997). The Myth of the A.D.D. Child: 50 ways to improve your child's behavior and attention span without drugs, labels, or coercion. USA: A Plume Book.

Armstrong, Thomas. (2001). Síndrome de Déficit de Atención con o sin Hiperactividad ADD/ADHD. Estrategias en el aula. Argentina: Paidós.

Barkley, Russell. (1998). Attention Deficit Hyperactivity Disorder: A Handbook for Diagnosis and Treatment. New York: Guilford.

Barkley, Russell. (1997). ADHD and the nature of self-control. New York: The Guilford Press.

Bauermeister, José. (2000). Hiperactivo, Impulsivo, Distraído ¿Me conoces? Guía acerca del déficit atencional para padres, maestros y profesionales. San Juan, Puerto Rico: Atención.

Bauermeister, José. (2001a). El trastorno por Déficit de Atención e Hiperactividad y las funciones ejecutivas: Pertinencia de una Nueva Teoría a Niños Hispanos. En Terremotos y Soñadores. Argentina: Publicación de la Fundación Trastorno por Déficit de Atención e Hiperactividad.

Bauermeister, José. (2001b). El déficit de atencional, nuestros niños, y la autoestima: ¿Qué podemos hacer? En Terremotos y Soñadores. Argentina: Fundación Trastorno por Déficit de Atención e Hiperactividad.

Bauermeister, José. (2003). Printing: El déficit de atención y las funciones ejecutivas. En CHADD Children and Aduls with Attention - Deficit/Hiperactivity Disorder. http://www.chadd.org/pritthis.cfm?cat id=13

Boujon, Ch y Quaireau, Ch. (1999). Atención, aprendizaje y rendimiento escolar. Aportaciones de la Psicología Cognitiva y Experimental. Madrid: Narcea S.A. de Ediciones.

CHADD. (2003). El trastorno llamado TDA/H. Hoja de Datos de CHADD \#1. http://www.chadd.org

CIMED. (2001). Información sobre el síndrome del déficit atencional. Uso de medicamentos como la Ritalina, Dexedrine, Dextrostad, Adderall y antidepresivos. Costa Rica: Facultad de Farmacia. Universidad de Costa Rica.

Clemes, H, Bean, R. y Clark, A. (1988). Cómo desarrollar la autoestima en niños y adolescentes. España: Editorial Debate S.A.

Colom, Roberto y Flores-Mendoza, Carmen. (2001). Inteligencia y Memoria de Trabajo: La Relación Entre Factor G, Complejidad Cognitiva y Capacidad de Procesamiento. Psicología: Teoría e Pesquita. 17(1): 037-047.

Craig, Grace. (2001). Desarrollo Psicológico. México: Prentice Hall. 
Fernández, Tubair. (s.f.). Los padres y el lenguaje del niño. Recuperado en setiembre del 2003, de http://lenguaje.4t.com.

Fowler, Mary. (1995). Desorden Deficitario de la Atención. USA, NICHCY: Briefing Paper.

Fundación Déficit de Atención. (2002). Página de internet. Argentina. http://www.TDAH.ar

García, Fernando. (2001). Es TDAH y ahora ¿qué? Trastorno de Déficit de atención/hiperactividad. Una guía básica. San Juan, Puerto Rico: Ediciones Hispalis.

García, Manuel. (2001). El Fracaso Escolar en educación primaria y secundaria y trastornos por Déficit de Atención con o sin hiperactividad. Recuperado de http://www.grupoalbor-cohs.com

García, Manuel y Magaz Lago, Ángela. (2000). Actualidades sobre el TDA-H. Recuperado en marzo 2003, de http://www.tda-h.com/actualidad.html

García, Manuel y Magaz Lago, Ángela (2001). Situación actual del Trastorno por Déficit de Atención con Hiperactividad (TDAH). Terremotos y Soñadores. Revista de la Asociación TDAH.

García, Manuel (s.f.) EI TDAH como una ventaja adaptativa. http://www.grupoalborcohs.com

Genaltruista.com (2000) Cerebro. Lavado de cerebro, desmantelamiento psíquico, indoctrinamiento. Recuperado en junio, 2006, de http://www.genaltruista.com/notas.

Goldstein, Sam (s.f.) EI TDAH como una ventaja adaptativa. Argentina: Publicación Electrónica de la Fundación Trastorno por Déficit de Atención e Hiperactividad. Recuperado el 12 de marzo, 2003, de http://www.tdah.org.ar/articulo 1.html.

González Dobles, Jaime. (1984). El diseño de un proyecto investigativo. Costa Rica: Ediciones Presencia.

Good, Thomas y Brophy, Jere. (1996). Psicología Educativa Contemporánea. México: Mc. Graw Hill.

Gratch, Luis Oscar. (2000). El Trastorno por déficit de atención (ADD-ADHD). Clínica, diagnóstico y tratamiento en la infancia, adolescencia y adultez. Argentina: Editorial Médica Panamericana.

Kirby, Edward y Grimley, Liam. (1992) Trastorno por Déficit de Atención. México: Limusa.

Mediavilla García, Cristina. (2003). Neurobiología del trastorno de hiperactividad. Rev Neurol. 36(6):555-565

Mendoza González, María Eugenia. (1999). La memoria. México: Lazos Edición Internet. Asociación Alzheimer de Monterrey, A.C. Boletín Informativo abril, mayo, junio, 1999/año 3, No. 19 http://www.geocities.com/lazosalzheimer/lazos-1999/lazos-19$\underline{07 . h t m l}$ 
National Institute of Mental Health. (2001). Trastorno Hiperactivo de Déficit de atención. http://www.nimh.gov/publicat/spadhd.htm

Papalia, Diane, Wendkos, Sally y Duskin, Ruth. (2001). Psicología del desarrollo. Colombia: Mc. Graw Hill.

Peña, Marina. (2001). Aprender diferente es común. Terremotos y Soñadores. Revista de la Asociación TDAH. 2(4).

Pineda, David. (s.f.). Las funciones ejecutivas. Recuperado de http://neurología.rediris.es/congreso1/conferencias/neuropiscología-2-4.html

Puente, Anibal. (2001). La Memoria: una compleja entidad difícil de evaluar. Terremotos y Soñadores. Revista de la Asociación TDAH. 2 (3).

Pueyo, R, et al (2000) Trastorno por déficit de atención con hiperactividad. Asimetrías cerebrales observadas en resonancia magnética. REV NEUROL: 30 (10): 920-925

Rief, Sandra. (1998). ADD/ADHD Checklist. An easy reference for parents \& Teachers. USA: Prentice Hall.

Santrock, John. (2001). Psicología de la Educación. México: Mc.Graw Hill.

Scandar, Rubén. (2000a). El niño que no podía dejar de portarse mal. TDAH: su comprensión y tratamiento. Argentina: Editorial Distal.

Scandar, Rubén (2000b). TDAH va a la escuela. Terremotos y Soñadores. Revista de la Asociación TDAH. 1(1).

Scandar, Rubén y Puente, Aníbal. (2003). ¿Cómo pueden los padres y docentes mejorar la autoestima de los niños? Terremotos y Soñadores. Revista de la Asociación TDAH. (5).

Shapiro, Lawrence E. (1997). La Inteligencia Emocional de los Niños. Una guía para padres y maestros. México: Javier Vergara Editor.

Sosin David \& Mira. (2001). Attention Deficit Disorder. USA: Teacher Created Materials, Inc.

Tannock, Rosemary y Martinussen, Rhonda. (2001). Reconceptualizando el Déficit Atencional. Educacional Leadership (pp. 20-25). Traducción libre de M.Ed. Marisol Nieto para uso en la presente investigación.

Vygotsky, Levy. (1978). Mind in society: the development of higher psychological processes. Cambridge MA: Harvard University Press.

Woolfolf, Anita. (1999). Psicología Educativa. $7^{a}$ ed. México: Prentice Hall Hispanoamericana, S.A. 